\title{
المراكز الثقافية في دفتر أوقاف الموصل المرقم 1/169 " بهدينان وأربيل والسليمانية نموذجاً \\ " دراسة تاريخية وثائقية " \\ ماجد محمد يونس
}

قسم التاريخ، كلية العلوم الانسانية، جامعة زاخو، أقليم كردستان العراق. (majid_zaxoy@yahoo.com)

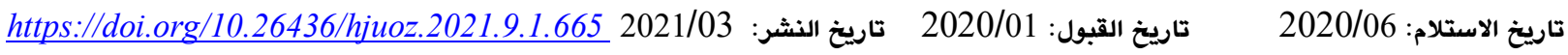

الملخص:

يُعد دفاتر الأساس من السجلات العثمانية المهمة التي تختص بدراسة الأوقاف والمؤسسات الوقفية والتي تحتوي على معلومات تاريخية

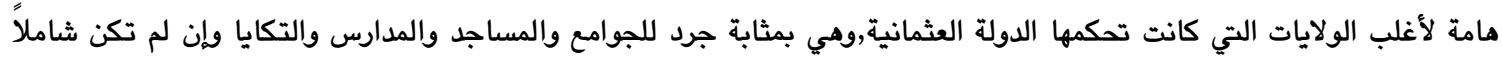

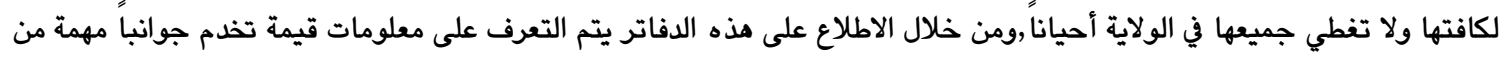

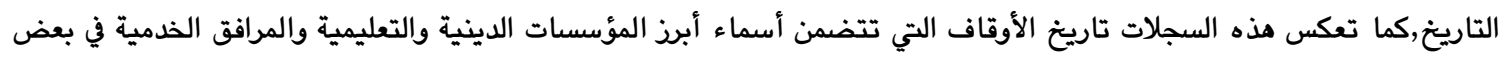

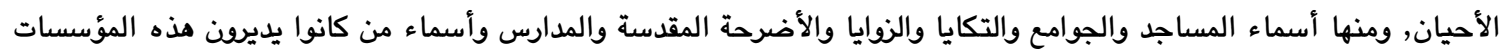
ونوعية علاقتهم بالسلطات الحاكمة,وفي بعض الأحيان أسماء من تبرعوا وأوقفوا أموالهم أو ممتلكاتهم لذدمة المؤسسات المذكورة. في

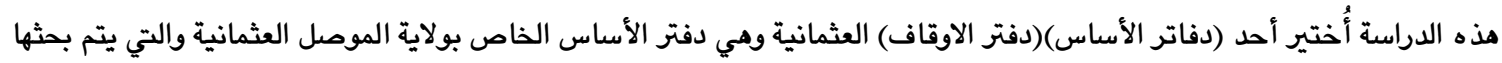

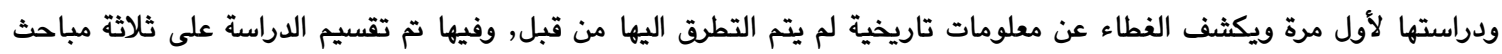

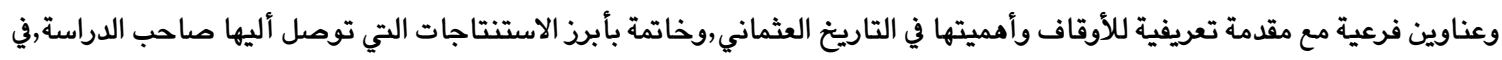
المبحث الأول منها والتي تحمل عنوان (بهدينان في دفترأوقاف ولاية الموصل) فيها تم تعريف ولاية الموصل وتاريخ ألتحاقها بالدولة العثمانية وتعريف بهدينان كجزء من الولاية المذكورة بشكل مبسط مختصر ليتم دراسة أهم المؤسسات الدينية والعلمية وأهم الوقفيات

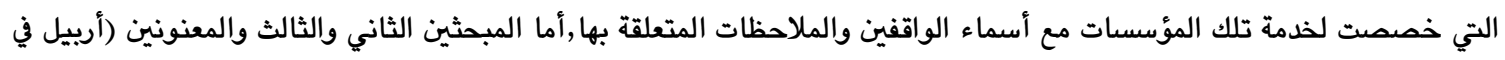
دفتر اوقاف ولاية الموصل) ,(السليمانية في دفتر أوقاف ولاية الموصل),ففيهما تم دراسة أهم المؤسسات الدينية والعلمية وأهم الوقفيات

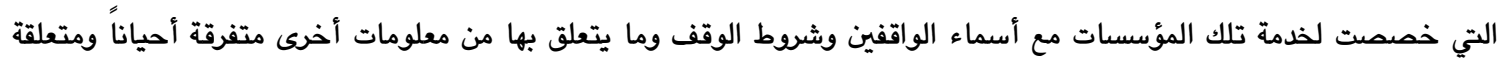

$$
\text { الكلمات الدالة: دفاتر الأوقاف، بهدينان، المساجد، أربيل، الدارس، ولاية الموصل. }
$$

وتمثل الأوقاف نظاماً أقتصادياً له مفهومه ووظائفه الخاصة منذ ظهوره

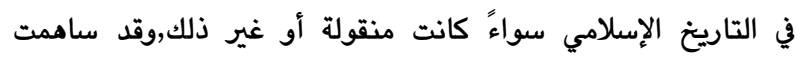

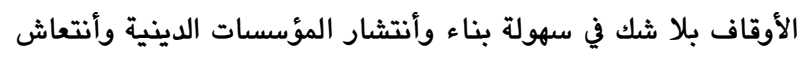

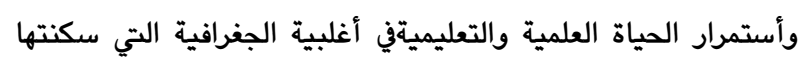

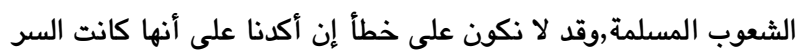

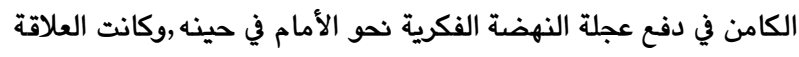
والإرتباط وثيقاً جداً بين المساجد والمدارس والتكايا والزوايا والطرق

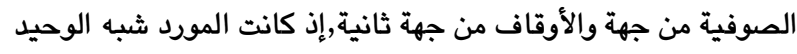

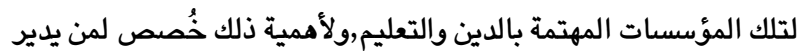
الأوقاف وظيفةً رسمية بأسم (ناظر الأوقاف).

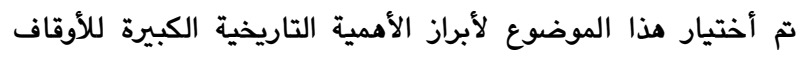

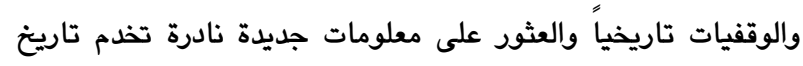

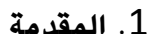

يعرف الوقف على انها حبس مال أو عقار ووضعها لخدمة مؤسسة

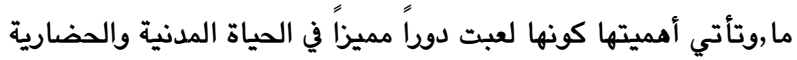

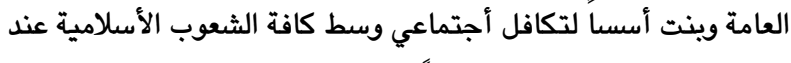

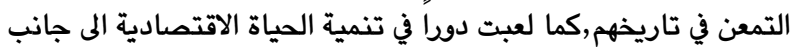

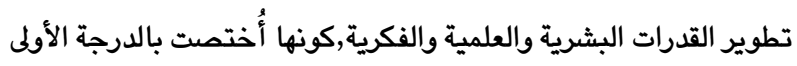

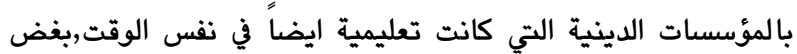
النظر عن المؤسسات التعليمية نفسها انذاك كالمدارس والكتاتيب التي التي التيان

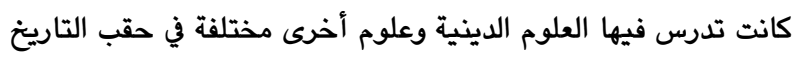

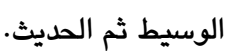


أما من حيث مصادر الدراسة من المهم التنويه أنه تم الإعتماد بالدرجة

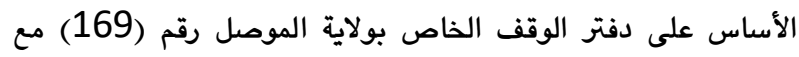

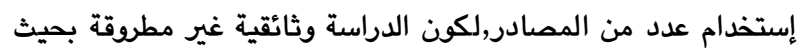

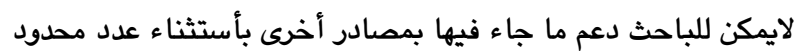
من المعنية منها بالتاريخ العثماني وموضوعة الوقفيات فيها ليتم تعريف وأيضاح نقاط مبهمة وتقريب الصورة بشكل أدق للقارئ والتي

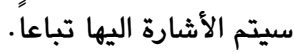

\section{2. بهدينان في دفتر أوقاف ولاية الموصل}

دخلت الموصل تحت النفوذ والسيطرة العثمانية سنة 1515 في أعقاب معركة جالديران التاريخية,وقد كانت لموقعها أممية قصوى للعثمانيين من الناحيتين السياسية والعسكرية,فقد كانت قاعدة للحملات العثمانية

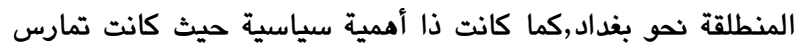

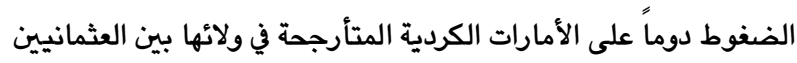
من جهة والصفويين الجاهدين الى توطيد أقدامهم بين الأمارات الكردية لقطع خطوط المواصلات للجيوش العثمانية من جهة ثانية, (علي,1985,ص153-154). شكلت ولاية الموصل لأول مرة في الربع الأخير من القرن السادس عشر

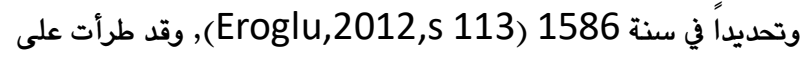

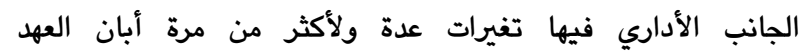

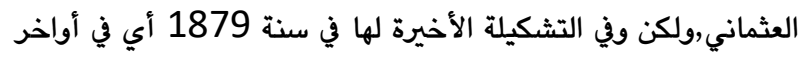
العهد العثماني كانت تتكون من ثلاثة سناجق,سنجق الموصل التئي

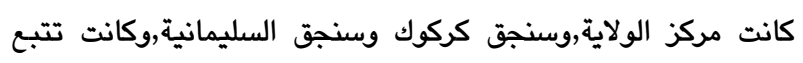
سنجق الموصل كل المنطقة أو الأقليم المسمى بيهدينان المتكون من

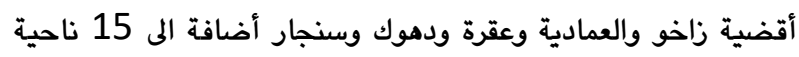
1598 قرية,فيما أتبعت سنجق كركوك أقضية رواندوز وأربيل

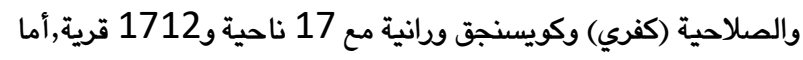
سنجق السليمانية فقد شملت أقضية كلعنبر (خورمال) وبازيان

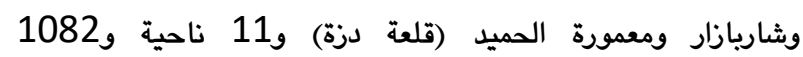

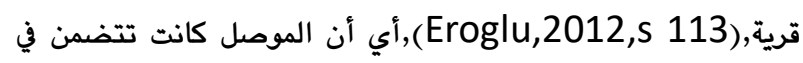

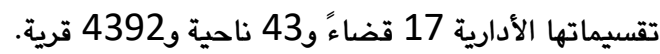
أما بهدينان فهي أسم لأقليم جغرافي محصور بين نهري الزاب الكبير شرقاً ودجلة غرباً وصولا الى الشمال من جبل مقلوب في كردستان

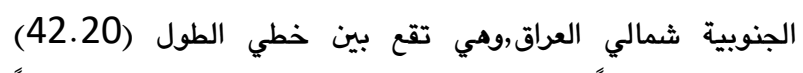
و44.10) شرقاً ,وبين دائرتي عرض (36.40) و(37.20) شمالاًا

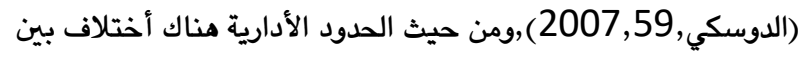

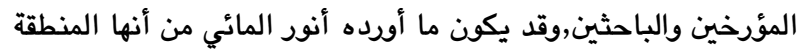
الممتدة بين أمارة سوران في الشرق وأمارة بوتان في الغرب,وأمارة مكاري في الشمال,وجبل مقلوب في الجنوب خلاصة كل الآراء المختلفة
الكرد الحديث في حقول معينة وخاصة في الشق العلمي والتعليمي منها ركما ان الدراسات الوقفية تقود الباحث التاريخي الى معرفة الادارة

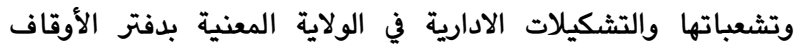
ومعلومات تاريخية مهمة متفرقة أخرى سيتم أظهارها والوقوف عليها

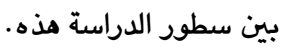
حصل الباحث على دفتر الأساس موضوعة الدراسة في الأرشيف

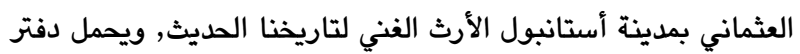
الأوقاف هذه رقم (1/169)من بين دفاتر الأوقاف في الأرشيف المذكور,وتخص ولاية الموصل وحدما والتي كانت إحدى أهم الولايات العثمانية,ويتكون من (160) صفحة عدا الجلد,وقد كتبت باللغة التركية العثمانية ولكن بالحروف العربية كغيرها من السجلات والدفاتر العثمانية المؤرشفة,وكل صفحة منها مقسمة الى حقول عدة,منها تسلسل

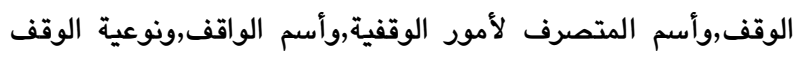

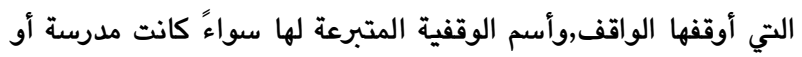

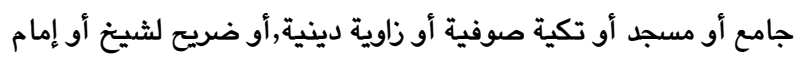

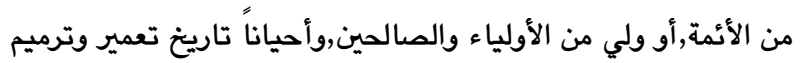

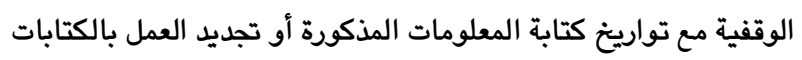

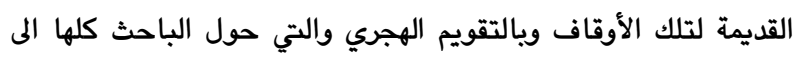
التقويم الميلادي ووضعها بين أقواس في صفحات الدراسة,كما انها تحتوي على تاريخ التبرع بالوقف وشروط الواقف وأهم الملاحظات التي

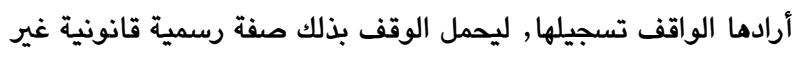

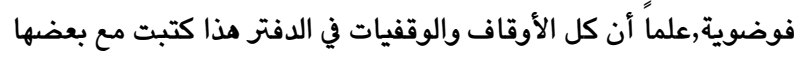

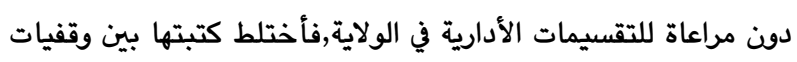
سناجق الموصل والسليمانية وكركوك بأقضيتها ونواحيها بل وقراها في بعض الأحيان مع بعضها دون خصخصة الدفتر حسب الوحدات

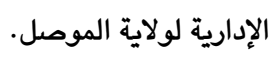
واجه الباحث بعض العراقيل أثناء دراسة هذا الموضوع,لعل من أبرزها كانت صعوية فك الخط التي كتبت بها الدفتر موضوعة الدراسة لكونها

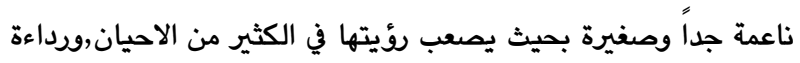
الخطوط التي كتبت بها,وأحياناً عدم فهم بعض دويتها في المواضيع وخاصة من الاحيان

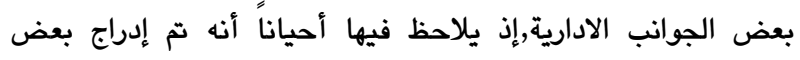

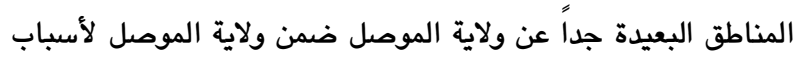

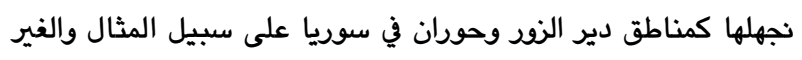
المرتبط إدارياً بهذه الولاية بالمطلق.

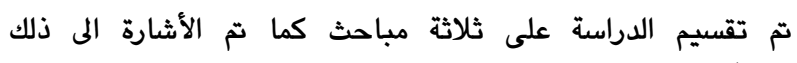

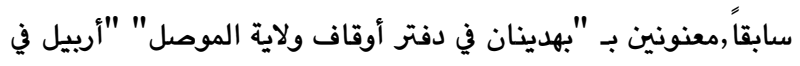
دفتر أوقاف ولاية الموصل "," السليمانية في دفتر أوقاف ولاية

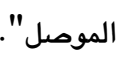


جاء ذكر مدرسة قبهان في دفتر وقف ولاية الموصل تحت التسلسل

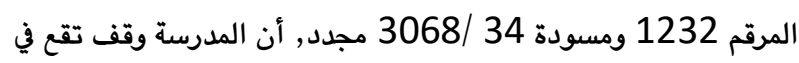
قضاء العمادية ضمن سنجق الموصل,ووفقاً لأمر الدولة العليةوبوصاية أن الدرسة

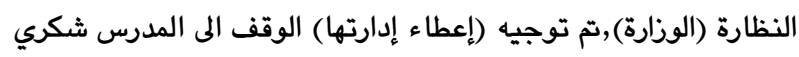

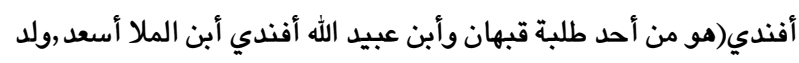

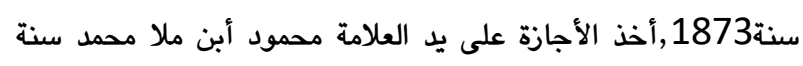

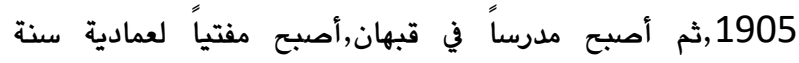

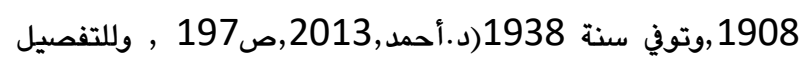

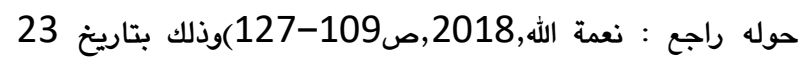

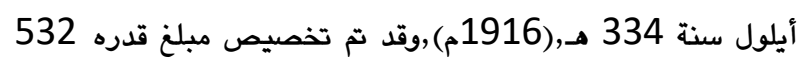

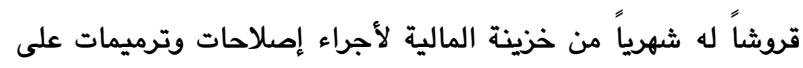

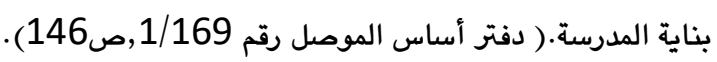

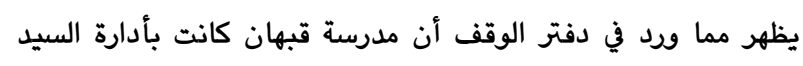

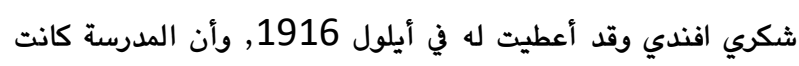

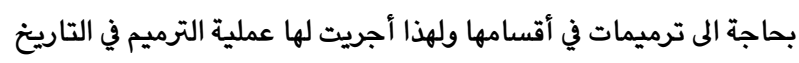
المذكور لأطالة عمرها, وقد تم تخصيص المبلغ المذكور من المال وضع تحت تصرف السيد شكري أفندي للأشراف على أعمال الترميم.

\section{ب. مدرسة الجديد :}

من المدارس القديمة والشهيرة في تاريخ الكرد الحديث,تقع في شمال

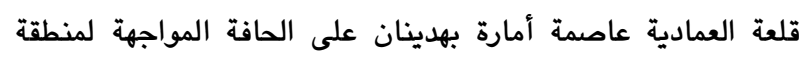

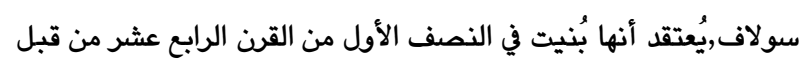

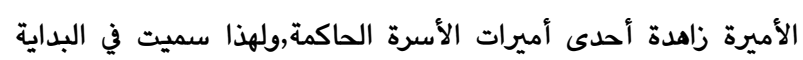
بالمدرسة الزاهدية,جددها الأمير سيدي خان أبن الأمير قباد بك أبن الأبرة المدين

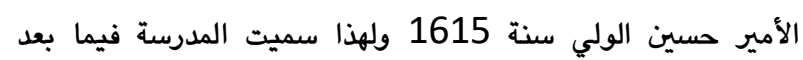

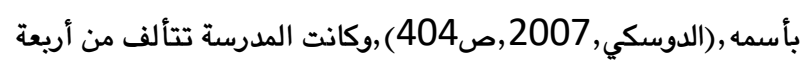

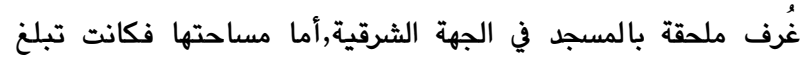

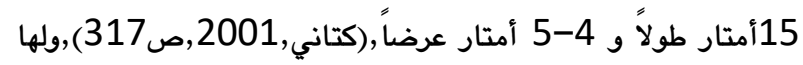
أسماء أخرى منها مدرسة الجديد ومدرسة الملا يحيى المنودي,وكانت

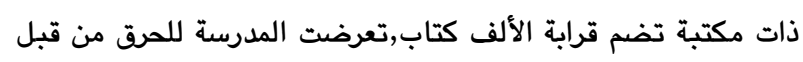
التياريين النساطرة وميليشياتهم المسمى بقوات الليفي الذي أسسها

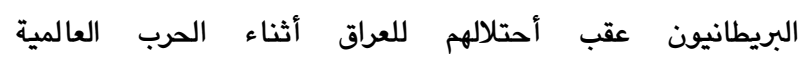

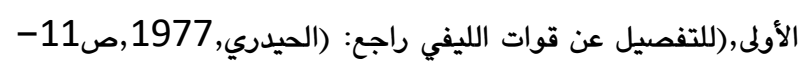
18),حُرقت المدرسة سنة 1920 في أعمال العنف التي كانت قائمة

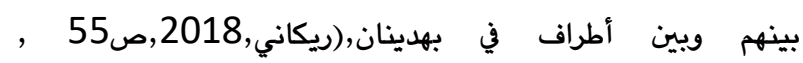
سعيد,2013,ص121). جاء ذكر مدرسة جديد في دفتر وقف ولاية الموصل تحت التسلسل

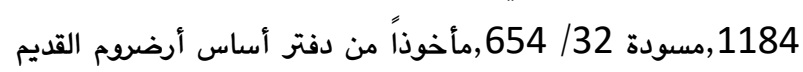

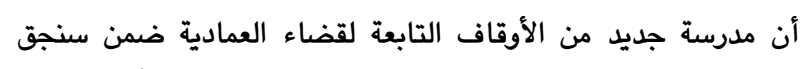

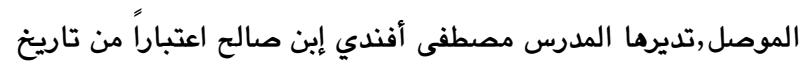

حول ذلك,(المائي,1999,ص38),وهي بمثابة مثلث أرضي كما

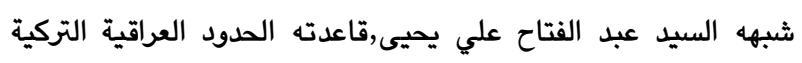

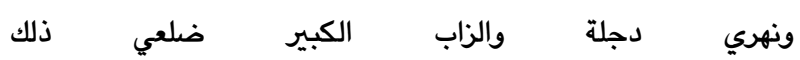
المثلث,(يحيى,1986,ص154),وقد قامت في بهدينان أمارة محلية

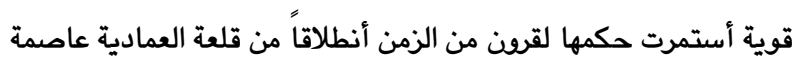

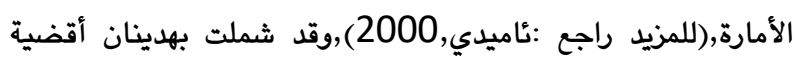
زاخو والعماديةوعقرة بالدرجة الأساس مع النواحي والقرى التابعة لهم

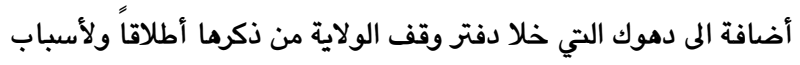
نجهلها حقيقة,ويسبب الموقع المتميز لبهدينان ومقوماتها الطبيعية

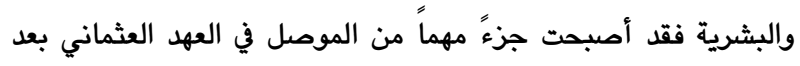
قضاء العثمانيين على الحكم الجليلي في الموصل سنة 1834 ثم أمثن

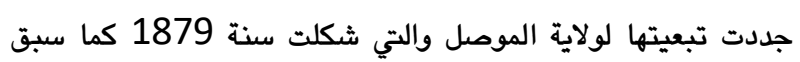

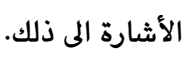

1.2. المدارس الوقفية في بهدينان:

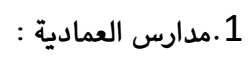
كانت العمادية أحدى أهم أقضية ولاية الموصل ويقع جنوب سنجق العقادية

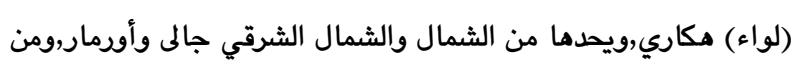

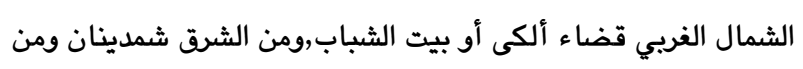

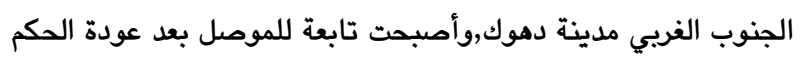
المركزي اليها سنة 1842,وفي سنة 1849 أصبحت تابعةً لولاية

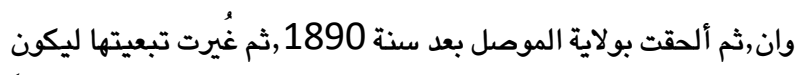
جزءً من سنجق كركوك سنة 1893 1أثم أعيدت المى ولاية الموصل مرةً

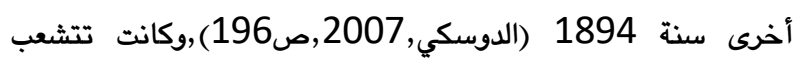
وتنقسم في أواخر العهد العثماني أدارياً على خمسة نواحي,ناحية برواري

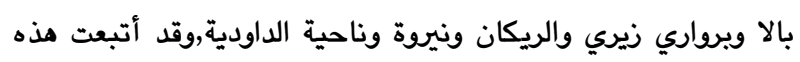

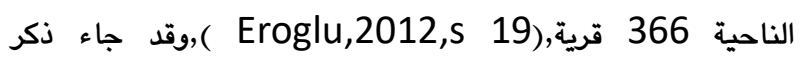
المؤسسات الوقفية فيها كالآتي : أ. ال مدرسة قبهان : تقع مذه المدرسة في قرية قبهان شمال غرب العمادية,وهي من أشهر المدارس التاريخية في منطقة بهدينان في تاريخه الحديث,وأحد أبرز

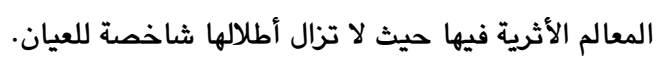

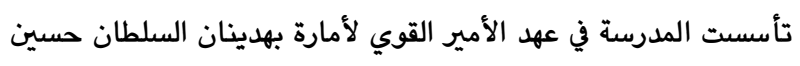

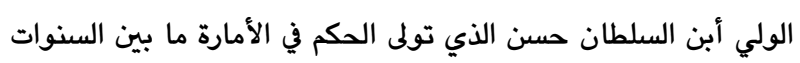

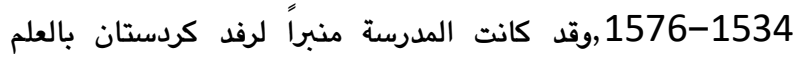

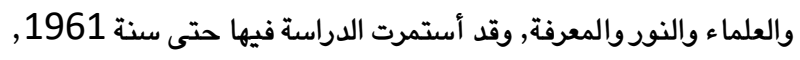

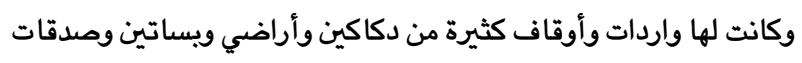

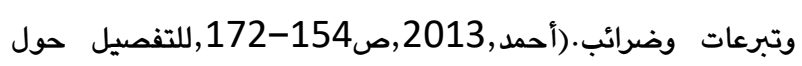
المدرسة راجع : بادي, 2018,ص 75-108). 
تسجيل هذا الأمر في 26 جمادي الأولى سنة 210هـ,(15 كماند 1892),كما تم تجديد ذلك ضمن أوداق نظارت المالية (وزارة المالية)

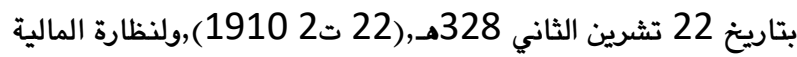

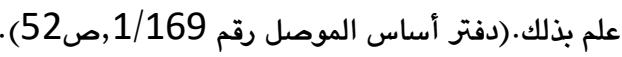

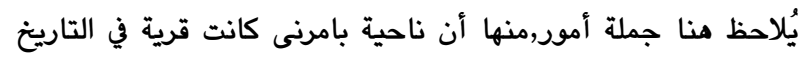

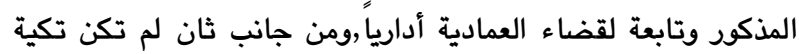
فقط,بل كانت مشيخة ومكاناً لدراسة ومناقشة العلوم وأعطاء الأجازات للفقهاء الذين كانوا يستوفون شروط الأجازة والأهلية العلمية,كما

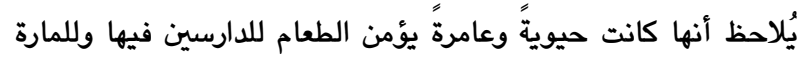

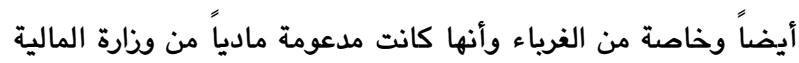
العثمانية عبر مالية سنجق الموصل.

2. جوامع ومساجد ومدارس عقرة :

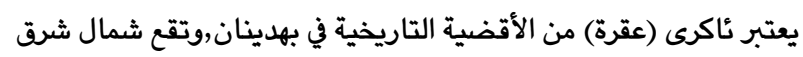
مدينة الموصل, يحدما من الشمال سهل زى وجبل شرين,ومن الجنوب جبل مقلوب,ومن الشرق نهر الزاب الكبير,ومن الغرب نهر الخازر

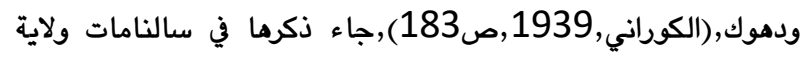
الموصل في نهايات القرن التاسع عشر بوصفها قضاءً تابعاً للولاية المذكورة,يتبعها نواحي العشائر السبعة والسورجي والزيبار(موصل سىى سالنامه ولايتي ولايتي 1308,1310,1312,ص117,ص169,ص279), مع 204 Eroglu,2012,s ( قرية كانت تابعة لعقرة والنواحي المذكورة 162),أما بخصوص المساجد والجوامع في عقرة والمذكورة في دفتر أوقاف الولاية فهي : المان

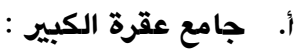
تعتبر من أحدى أقدم الجوامع في قضاء عقرة,ورد في دفتر أوقاف ولاية الموصل معلومات جيدة حولها مقارنة بغيرها من المؤسسات الوقفية,فجاء تحت التسلسل رقم 623,مسودة 2526/31 أنه تم

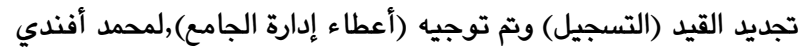

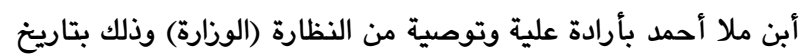
12 رمضان سنة 331هـ,(14آب1913) بصفتي الإمامة والخطابة, وقد وظف مقابل 33 ليرة شهرياً, ثمث غُير المبلخ ليصبح 80 ليرة مقابل

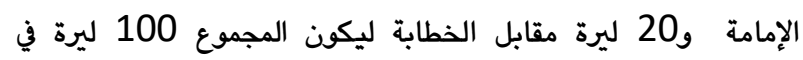

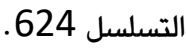
ويمقتضى أمر آخر كان قد جدد القيد (التسجيل)لهبت الله أفندي إبن محمد سعيد,(هو حفيد الملا يحيى المزوري,من مواليد سنة 1879, عُين مفتياً لقضاء عقرة سنة 1924, وعضواً في مجلس الأعيان

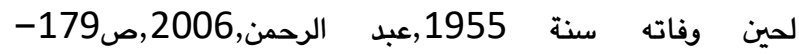
180),بأرادة علية وتوصية من النظارةمدرساً فيها تحت التسلسل

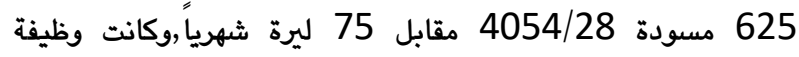

22 ذي القعدة سنة 290هـ,(10 ك2 1874),ثم يؤكد الدفتر في خانة الوقوعات على أن المشار اليه توفي وتم توجيه (أعطاء إدارة الوقف) بأمر من الدولة العلية الى خليفته جواد أفندي بتوصية النظارة

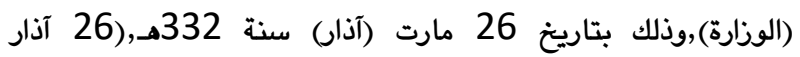
1913),وقد كُتبت تحت خانة الملاحظات ملاحظة قصيرة حول المدرسة ولكنها لا تُقرأ بسبب تهالك الورقة.(دفتر أساس الموصل رقم 1/169,ص140).

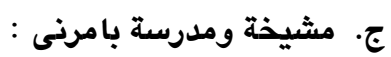

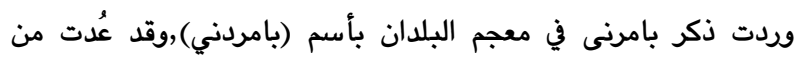

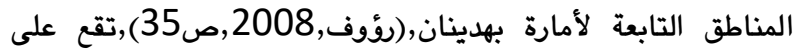
سفح جبل متين ضمن جغرافية قضاء العمادية,وتبتعد عن مركز قضاء

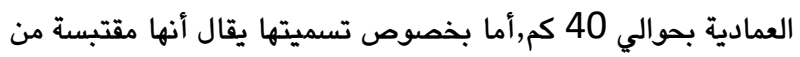

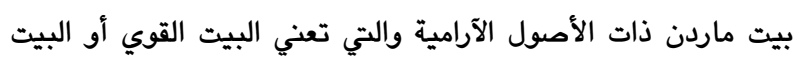
الحصين (بابان,1986,ص69), أما أهالي بامرنى فيرجحون أن كلمة بامرنى مكونة من مقطعين (با) والذي تعني الهواء و(مرنى) والتي تعني الموت,ويدمج الكلمتين ينتج عنها (هواء الموت أو ريح الموت). أُسست تكية بامرنى من قبل الشيخ طاهر النقشبندي (17831842) في النصف الأول من القرن التاسع عشر والمنتمي الى قرية

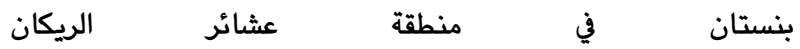
الكردية,(بامرني,2004,ر69),وكانت بعض القرى في مناطق الريكان

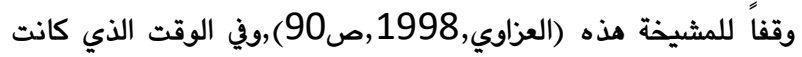
مدرسة لطلبة العلم وتكية للصوفيين كانت بمثابة مكان لأيواء المارة

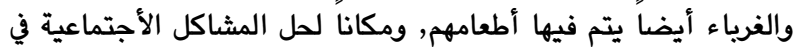

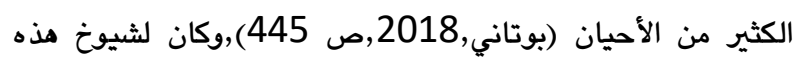

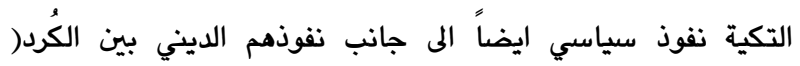

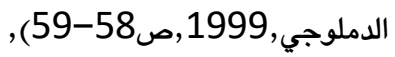
وقد ذكرها دفتر أوقاف ولاية الموصل على انها مشيخة,(والمشيخة في

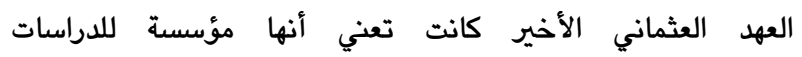

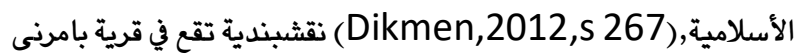

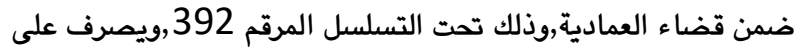

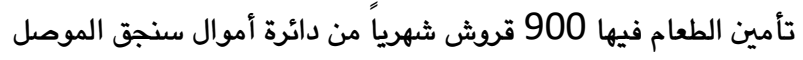
ويتصرف الشيخ محمد أفندي (كان السلطان عبد الحميد الثاني 1876-1909 قد منحه وقف أراض فأكتسبت التكية بذلك شهرة واسعة),(نعمان,2018,ص956),وقد تم تجديد العمل بذلك لأبنه

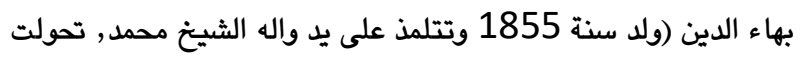

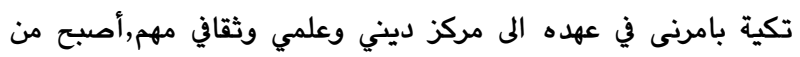
الشخصيات الفعالة في منطقة بهدينان وتزعم حركة المقاومة ضد الأنكليز في المنطقة سنة 1919,توفي في

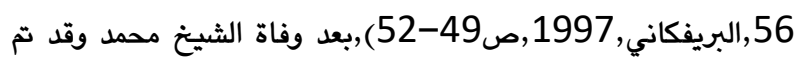


آذار 1913),دون أن يتم الأشارة الى نوعية الوظيفة المكفولة بها .(دفتر

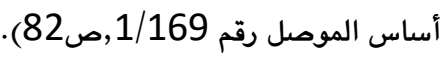
عند التأني فيما جاء بخصوص جامع عقرة الكبير يمكن التوصل الى

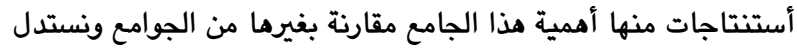
ما ذهبنا اليه من خلال ملاحظة كثرة ما ورد من معلومات مفصلة حولها

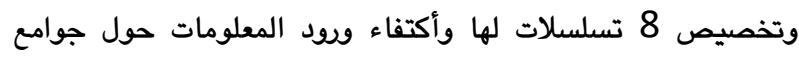
أخرى بشكل مختصر وفي تسلسل واحد أحياناً,كما أن كثرة التخصصات في الجامع مقارنة بغيرما مثل وظائف (مدرس ثان,مؤذن

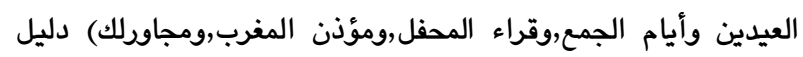

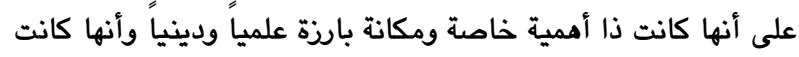
منتجةً جداً أذا ما علمنا أن جميع تلك الوظائف المذكورة أديرت من الهن قبل رجل دين واحد فقط في غيرها من الجوامع.

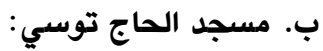
وتسمى بأسم مسجد حاجيان أيضاً,وهي من المساجد التاريخية في توني

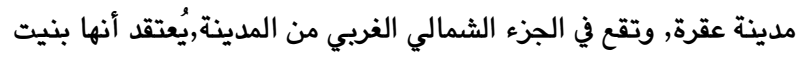

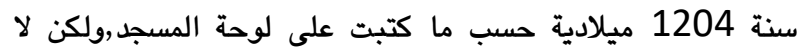

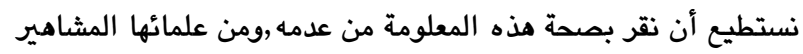

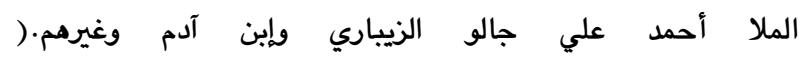
ريكانى,2019,ص16). يحتوي دفتر أوقاف ولاية الموصل على معلومات قليلة حول هذا

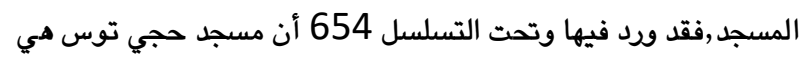
ضمن أوقاف ولاية الموصل,وأن المسجد تقع في قصبة عقرة,وأنه تم

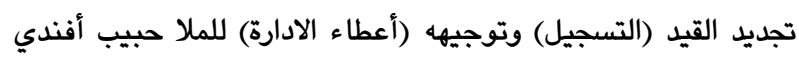

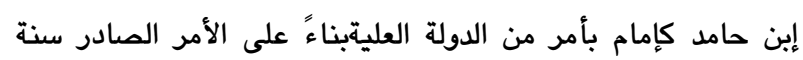

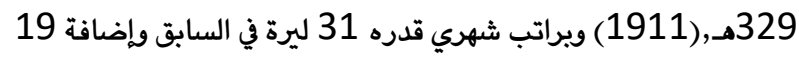

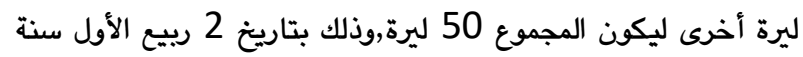

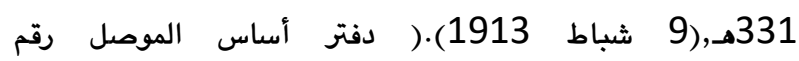
1/169,صه8). أما وظيفة المؤذن فقد جدد بموجب دفتر الوقف وتحت التسلسل

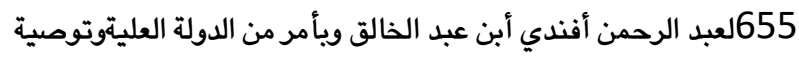

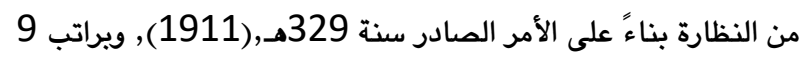

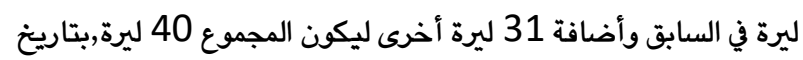
7 ربيع الاخر سنة 3313ـ,(16 آذار 1913).( دفتر أساس الموصل

$$
\text { ت. رقم 1/169,صجد جُستَيا : }
$$

من المساجد التاريخية القديمة في قضاء عقرة,ورد ذكرها في دفتر أوقاف

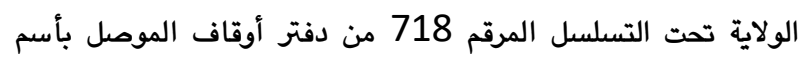

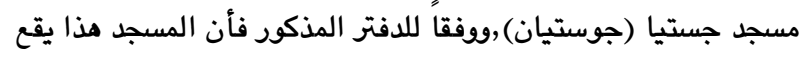
في مركز مدينة عقرة,وهي من ضمن أوقاف ولاية الموصل,وقد شملت
التدريس قد أضيفت منذ سنة 327هـ,(1908),وقد سجل هذا بتاريخ 12 محرم سنة 331هـ,(21 ك1 1912). وجاء تحت التسلسل 626 مسودة 237/29 أنه تم تجديد القيد بأمر من الدولة العلية وتوصية من النظارة لحجي ملا محمد أفندي أبن ملا

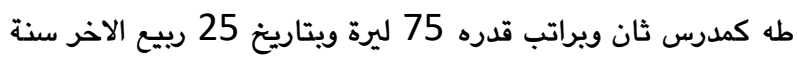
331 3ـ, (2 نيسان 1913).

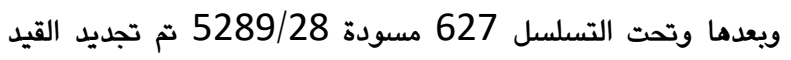

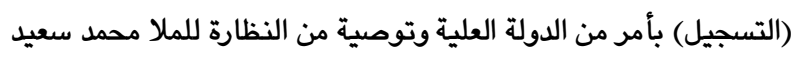

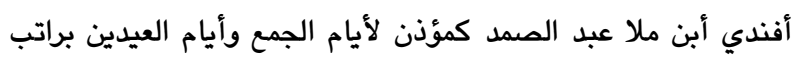

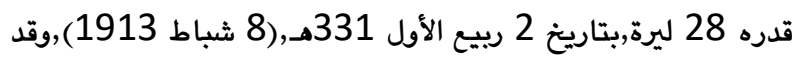
ورد في خانة الوقوعات مسودة 4681/31 من هذا الدفتر أنه وبعد وفاة الطباة

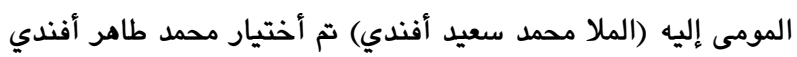

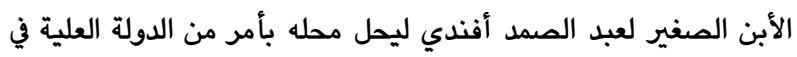

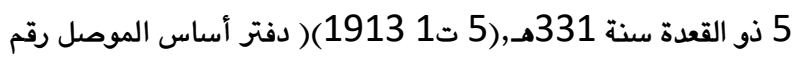

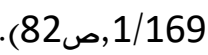

ثم يأتي الدفتر ليلقي الأضواء على وظائف أخرى في جامع عقرة الكبير,ففي التسلسل 632 مسودة 243/29 جاء أنه تم تجديد تسجيل وظيفة "قارئ المدفل" (قارئ الأجتماعات والمناسبات) والذي أضيفت الى الوظائف الأخرى منذ سنة 327هـ , (1908) لمحمد سليم أفندي أبن الملا علي بتوجيه وأرادة عليةوبراتب شهري قدره 37

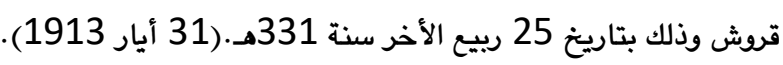
وفي التسلسل الذي يليه 633 مسودة 2521/31 تمت ودئ الأشارة الى

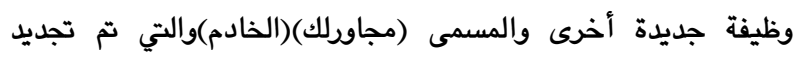

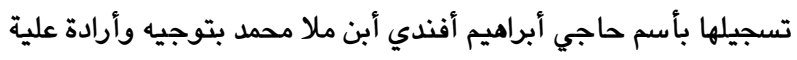

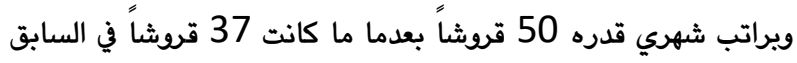

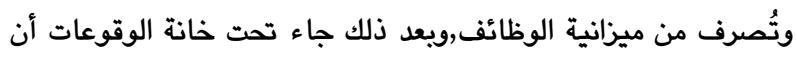
المومى اليه توفي ولذلك تم توجيه الوظيفة لأبنه الملا صديق أفندي

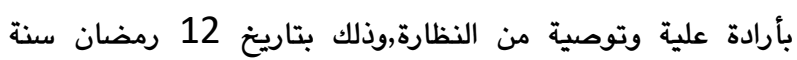
333هـ,(23 حزيران 1915).

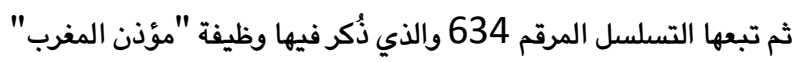
وقد تم تجديد تسجيلها بأسم محمد طاهر أفندي بتوجيه وارادة علية

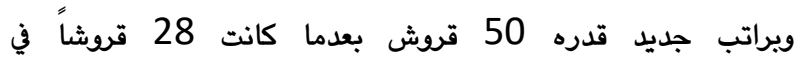

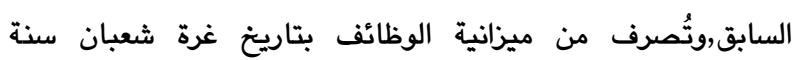

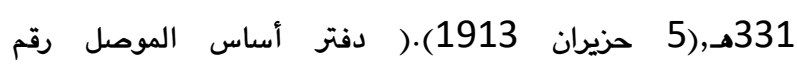

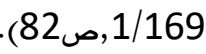

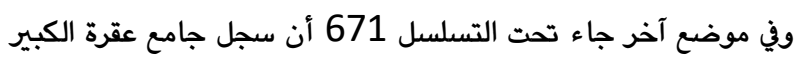
جُدد للحاج الملا محمد أفندي أبن الملا طه أفندي بأمر وأرادة الدولة

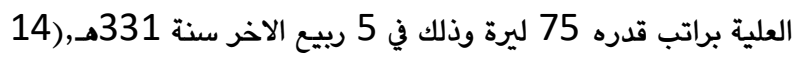




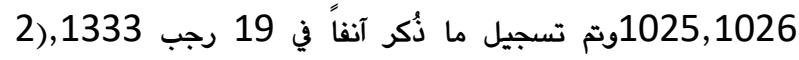
حزيران 1915).(دفتر أساس الموصل رقم 1/169,صال1020 120).

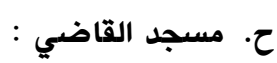

من المساجد التاريخية أيضاً في عقرة, ورد ذكرها في دفتر أوقاف الولاية

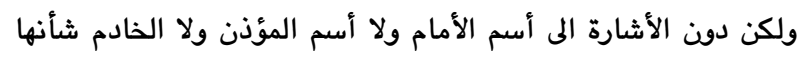

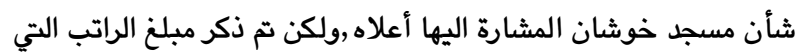

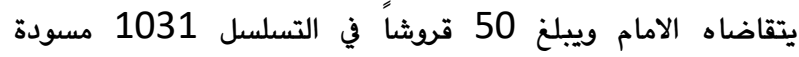
1234/28 كما أن راتب المؤذن والخادم معاً يبلغ 40 قروشاً شهرياً

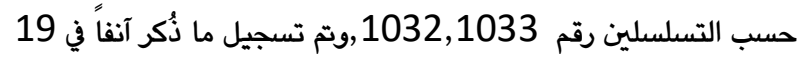
رجب 1333,20 حزيران 1915).(دفتر أساس الموصل رقم 1/169,ص120)

3.جوامع ومساجد ومدارس زاخو :

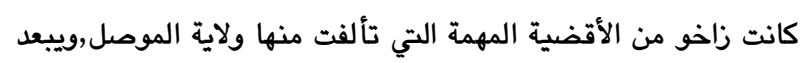
عن مركز الولاية بحوالي 110 كم,وقد كانت المدينة تشغل أقصى الشمال الغربي لهذه الولاية أبان الحكم العثماني لها بعد معركة جالديران ولغاية سنة 1918,أذ جاورها من الجنوب والجنوب الشرقي مدن دهوك والعمادية,ومن الشمال ولايتي وان وهكاري,ومن الشمال الغربي ولاية

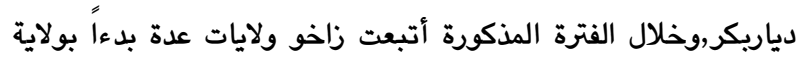

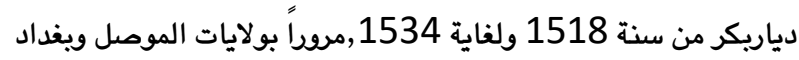
وشهرنور لمرات وأزمنة مختلفة مختلفة,ليصبح جزءً من ولاية الموصل

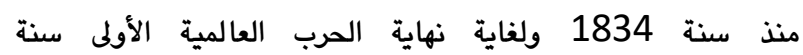
69 1918. (كولي,الجوادي,2019,ص27, سلد الكوراني,1939,ص183-184),وكانت تتبعها ناحيتي سليفاني وسندي كلي مع 181 قرية (الدوسكي,2007,ص197-198),أما المساجد والجوامع والمدارس المذكورة في دفتر أوقاف الولاية فهي :

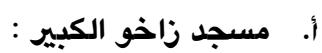

من المساجد الشهيرة في قضاء زاخو,يقع في مركز المدينة على مقربة من القشلة العثمانية في حي السوق أو في (سيكا تارى)(السوق المظلم) كما يسميه أهالي المدينة وذلك بسبب ضيق ممرات السوق الأمر الذي يؤدي الى قلة وصول أشعة الشمس اليها فتبدو وكأنها مظلمة قليلاً مقارنة بالأسواق الحديثة في المدينة. وفي الوقت ذاته كان جامع زاخو الكبير مدرسة ومنبعاً للعلم والعلماء,ومن مدرسيها المشاهير الملا عبد الله الحاج قاسم الزاخولي الذي عُين مدرساً للجامع سنة 1909 وتوفي سنة 1914, والملا أحمد المد

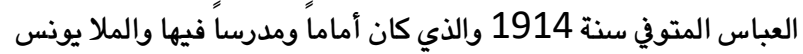
طه الزاخولي المتوفي سنة 1923,والملا أحمد أبن عبد الخالق العقري المتوفي سنة 1958,والملا صالح المهاجر المتوفي سنة 1976,والملا أسماعيل النافشكي $1994 \quad$ وغيرمم
المسجد ثلاثة وظائف,أولها هي وظيفة الإمامة التي تم تجديد قيدها (التسجيل) وإعطائها لعبد الففار أفندي إبن معاذ بأمر من الدولة العلية, بناءً على الأمر الصادر سنة 327هـ,(1909),براتب قديم قدره 15

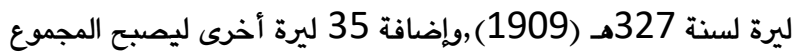
50 ليرة عثمانية,بتاريخ 26 جمادي الاولى سنة 331هـ,(3 أيار

ثم جاء في التسلسل 720 أنه تم تجديد التوجيه (إعطاء) وظيفتا المؤذن والخادم أيضا للمومى إليه عبد الغفار أفندي براتب شهري قدره

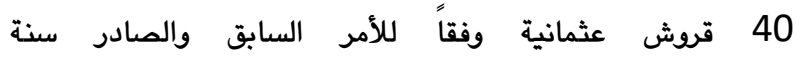
328هـ,(1910),وقد كتب في الدفتر في خانة الملاحظات أن المؤذن ولن والخادم لم يلتزما بوظيفتهما وعليه تم تكليف الأمام (عبد الغفار افندي)

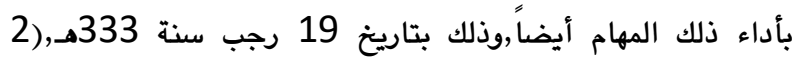

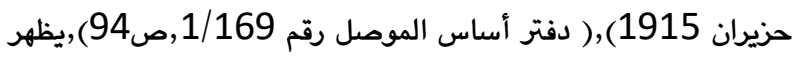
مما سبق ان الملا عبد الففار أفندي أبن معاذ كان يقوم بتأدية كافة الخدمات في المسجد المذكور.

ث. مسجد قرية باشقال آغا : قرية باشقال آغا من إحدى القرى التابعة لقضاء عقرة وهي من قرى عشيرة الزيبار الكردية, تقع القرية جنوب شرق مدينة عقرة,وقد أحتوت دفتر أوقاف ولاية الموصل على بعض المعلومات حول مسجدها,ففي التسلسل المرقم 754 أُشير الى محمد نوري أفندي كإمام تّ تجديد

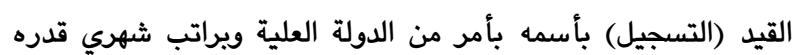
100 قروش بتاريخ غرة شعبان 331هـ,(6 تموز 1913). ويخصوص المؤذن للمسجد جاء أن تلك الوظيفة أيضاً وجهت (أعطيت) للمومى اليه محمد نوري أفندي براتب قدره 50 قرشاً في الشهر تحت التسلسل 755 وينفس التاريخ المذكور.(دفتر أساس الموصل رقم (98, 1/169

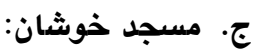

من المساجد التاريخية في عقرة,كانت تقع في مركز المدينة المذكورة,ولكن لا وجود لها الان في مركز القضاء لأسباب غير معروفة, ولكن هناك حي بأسم حي أومر خوشان في مركز القضاءروالراجع أن المسجد التاريخي أزيل من مكانها أو هدم ويني في مكانها مسجدُ آخر ويأسم ثان غير الاسم الأول. تمت الأشارة اليها بأقتضاب في دفتر أوقاف ولاية الموصل,ولكن من الدول الغريب أن الدفتر المذكور لا يشير الى أسم الأمام ولا الى أسم المؤذن ولا الخادم لأسباب نجهلها,بل كل ما ورد فيها تحت تسلسلها المرقم 1024 أن الراتب الشهري للأمام كان 31 قروشاً في السابق أُضيفت

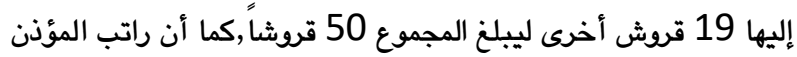
والخادم معاً كان يبلغ 25 قروشاً شهرياً في السابق فأضيفت اليها 15

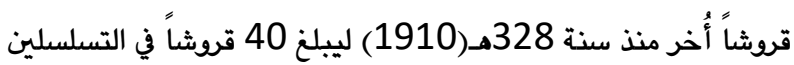


الجوامع والأشارة الى تفاصيل غير موجودة في غيرهما كوجود وظيفة

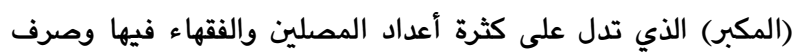
مصاريف المحروقات والغاز وأواني الأكل تظهر عظم شأنهما وتميزهما عن أخواتهما من المؤسسات الدينية والعلمية.

\section{3. أربيل في دفتر أوقاف ولاية الموصل}

تقع أربيل بين الزابين الأعلى والأسفل,يحدما من الشمال تركيا ومن

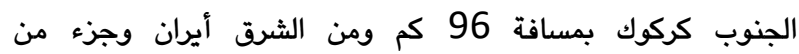
السليمانية,ومن $86 \quad$ الغرب كم,(الحسني,1956,ص235), دخل العثمانيون اليها في عهد السلطان سليمان القانوني سنة 1534 في حملته التي أستولى خلالها على بغداد وكانت آنذاك جزءً من أمارة سوران (أسماعيل,1970,صكئه 266),وفي سنة 1586 كانت واحدة من السناجق الثمانية التي تشكلت منها أيالة الموصل (Eroglu,2012,s 14),ثم أصبحت جزءاً مهماً من أراضي أمارة سوران مرة أخرى والتي قضى العثمانيون عليها في أواخر النصف الأول من القرن التاسع عشر بقضائهم على أميرها الشهير اهري

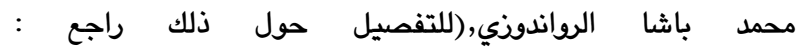
أسماعيل,1970,ص2326-341), فأصبحت أربيل بعد ذلك من أحدى الأقضية التابعة أدارياً لسنجق كركوك ضمن ولاية الموصل في أواخر العهد العثماني,وقد تمت الأثارة الى عدد محدود من جوامع ومساجد وتكايا أربيل في دفتر أوقاف الولاية وهي :

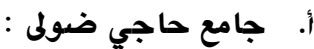

ورد ذكر قلة من المؤسسات الوقفية في أربيل في دفتر أوقاف ولاية الموصل مقارنة بكركوك والسليمانية لكون الأخيرتين كانتا مركزين لسنجقين مهمين ضمن ولاية الموصل التي كانت تتألف من ثلاثة سناجق والموصل عاصمتها,بل كانت أربيل قضاء" ضمن سنجق كركوك.

وأول ذكر لأربيل في دفتر وقف الولايةجاء بخصوص جامع حاجي جولي الواقع في حي التعجيل قرب منارة المظفرية, التي أسست سنة 1881 بقرار من الشيخ جولي المتوفي سنة 1890 والمدفون في الجامع نفسه وييلغ مساحتها قرابة 1000متر مريع,ومن أبرز الملالي والمدرسين فيها بعد الشيخ جولي هم (الشيخ مصطفى أبن الشيخ جولي,الملا أسماعيل ملا قوجة,الملا حمد أمين أبن الملا محمد كونفلوسة,الملا عبد الله أبن الملا حمد أمين,والملا علي أبن الملا عبد

$$
\text { الله),(برزنجي,2001,صونسك). }
$$

أُشير الى هذا الجامع تحت التسلسلات 447 و448 و449,ورود أنه تم تجديد القيد (التسجيل) للشيخ مصطفى أفندي إين الشيخ محمد جولي أفندي ويالخط الهمايوني (بأمر سلطاني رسمي) كخطيب لجامع حاجي جولي المشهور وذلك في 8 صفر سنة 1316هـ,(27 حزيران
(رؤوف,2008,ص187), (أحمد,2013,ص142),وقد أستمرت

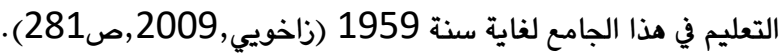
أشُير اليها في دفتر الأوقاف تحت التسلسلات 861 و862 و 863 و864 و865 على أنها داخلة ضمن أوقاف ولاية الموصل بأسم الجامع الكبير في قضاء زاخو وفيها وظائف الأمام والخطيب والمدرس والمؤذن ولن

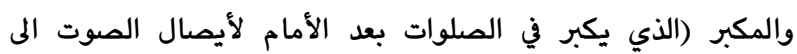
المصلين) والخادم ووظيفة "محفل خوان" (أدوات وأواني محافل

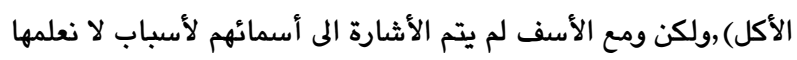
في الحقيقة,وجاء فيها أن رواتب كل من الامام والخطيب والمدرس مجتمعة في السابق كانت تبلغ 1800 قروشاً, أضيفت اليها 2000 قروش ليصبح مجموعها 3800 قرش, أما رواتب المؤذن والمكبر والخادم فكانت 1000 قروش في السابق فأضيف اليها 1400 قروش فروشي

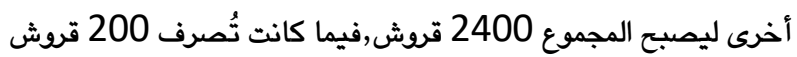
في السابق لوظيفة "محفل خوان" فأضيفت اليها 600 قروش ليكون المجموع 800 قرش,وقد حدث تلك التغيرات بأمر من النظارة (الوزارة) الجليلة في 8 حزيران سنة 331هـ,(1912),وذلك بعدما تم مرون أعلام مديرية المحاسبات العامة بذلك سابقاً في 23 ت2 233 سنة سنة 330هـ,(1911),(دفتر أساس الموصل رقم 1/169,صدمئ1112).

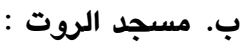

من المساجد التاريخية القديمة والتي كانت مدرسة في الوقت ذاته في مدينة زاخو,وتقع في محلة الروت (يسميها أهالي زاخو محلا رويتا) أحدى المى أقدم الأحياء السكنية في المدينة وتقع الجامع على حافة نهر الخابور مباشرة وعلى مقربة من جسر الفاروق الذي يربط حي الروت وحي اليهود القديمتين من جهة الشرق بحي النصارى من جهة الغرب. جاء ذكرها في موضع واحد بدفتت أوقاف ولاية الموصل,حيث ذُكر تحت من من

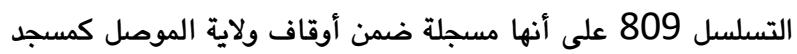
في حي الروت في قضاء زاخو دون الأثارة الى أسم الإمام أو المؤذن أو أو اله

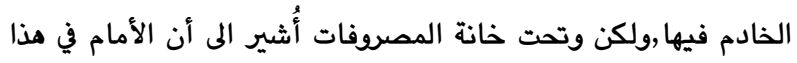
المسجد يأخذ 400 قروش شهرياً,وتحت خانة الملاحظات من الدفتر جاء تم تسجيل مصاريف المسجد والمدرسة بموجب قرار الخزينة ولكي تبقى المسجد عامراً يتم صرف تَّئ 700 قروش سنوياً للأمامة وخدمات الآذان و150 قروشاً كمصاريف سنوية للغاز والمحروقات,و100 قروش لخدمات أخرى في المسجد,ثم ذلك بعلم دائرة المحاسبات العمومية,19 جمادي الآخرة سنة 332هـ,(14 أيار 1914).(دفتر أساس الموصل رقم 1/169,ص104). ويبدو أن جامع زاخو الكبير ومسجد الروت كانتا من ضمن الجوامع المهمة في ولاية الموصل والدليل على ذلك هو وجود كافة الوظائف فيهما والتي تدل على أنهما كانتا فعالتين ونشيطتين في مجال نشر العلوم

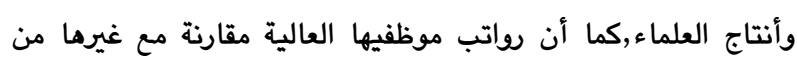


الخطابة ففي تاريخ 1913 1913) بأمر همادي الاولى سنة 331هـ,7 نيسان 1913),بأمر همايوني (بأمر سلطاني رسمي).

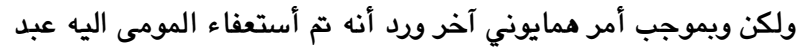

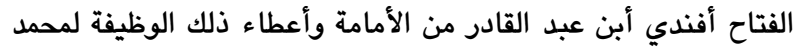

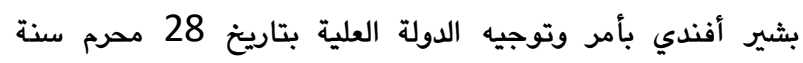
333هـ,(15 ك1 1914),كما تم أستعفائه أيضاً من وظيفة الخطابة وأعطائها لمحمد بشير أفندي بالخط الهمايوني (بأمر سلطاني

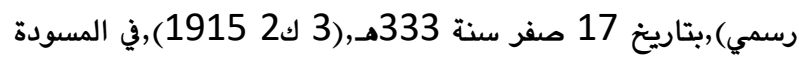

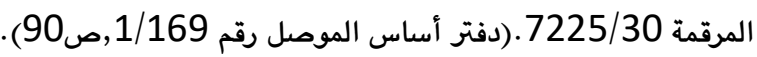

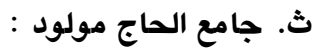

من الجوامع التاريخية الشهيرة في مدينة أربيل وتقع قرب القلعة,وللجامع

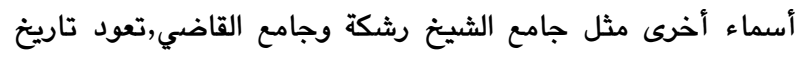
تأسيسها الى سنة 1910 بنفقة خاصة من الحاج مولود,ويبلغ مساحتها

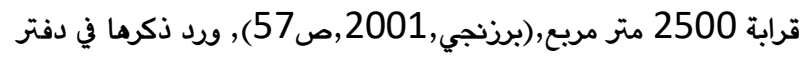
أوقاف ولاية الموصل ويتسلسلات مختلفة.

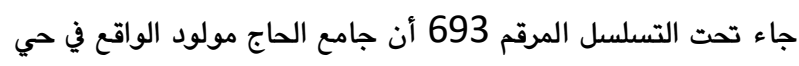

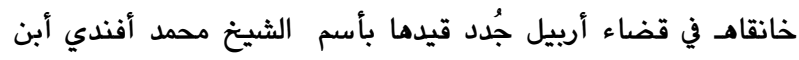
الشيخ أسعد أفندي مشروطياً بأرادة وأمر الدولة العلية ليتولى أمرها

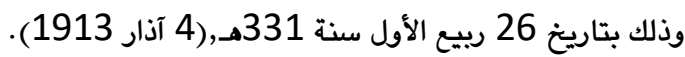

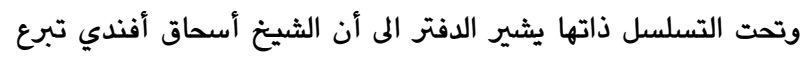

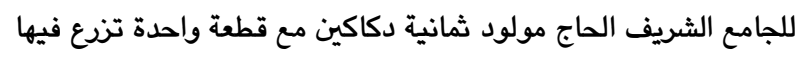
الخضراوات كوقف للجامع المذكور بتاريخ 26 ربيع الأول سنة

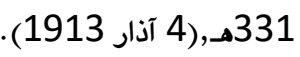

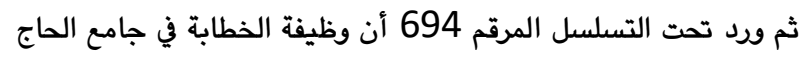

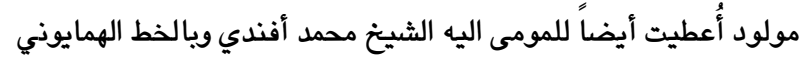

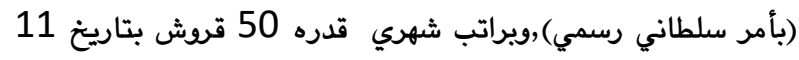
ربيع الاخرة سنة 331هـ,(19 آذار 1913). وفي التسلسل 695 جاء أن المومى اليه الشيخ محمد ألفار أفندي أُعطي

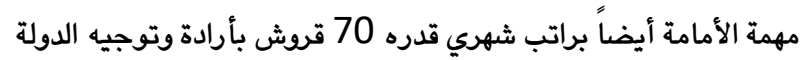

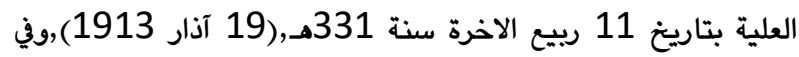
التسلسل الذي يليه جاء أن وظيفة المدرس أيضاً أعطي للشيخ المذكور

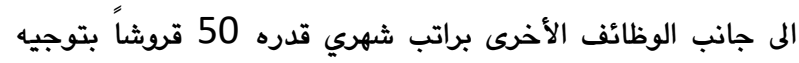
الدولة العلية, وكذلك وظيفة المؤذن في التسلسل 697 براتب قدره 20 ترات

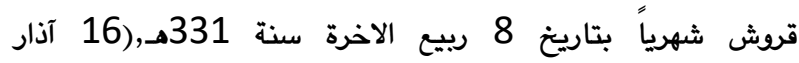
1913).(دفتر أساس الموصل رقم 1/169,صبعائ

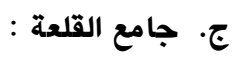
تعتبر قلعة أربيل من أبرذ المعالم التاريخية في المدينة,وهي من أقدم المدن التي أستمر أستيطان الأنسان فيهاريبلغ مساحتها قرابة الترانيا 60000متر مربع,وهي بقايا مدينة آشورية كانت تعرف بأسم (أربا الانيان
1898),كما تم تجديد القيد له كأمام ومؤذن للجامع المذكور بتاريخ 28 شعبان سنة 116هـ,(10 ك2 1899),وأن أصحاب الخيرات

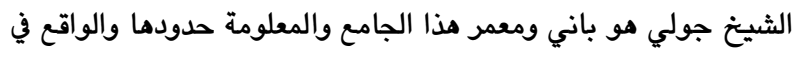
حي العرب في قضاء أربيل ضمن ولاية الموصل,كما أوقف قطعة أشجار

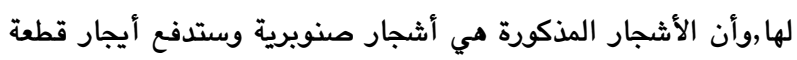

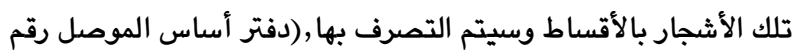

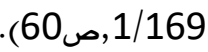
ب. مدرسة الواعظ أحمد أفندي :

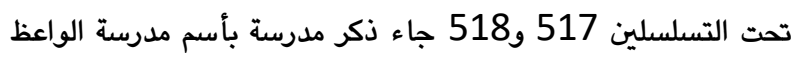
أحمد أفندي,الواقع في قضاء أربيل في سنجق كركوك,وفيها تمت الأشارة الى أن نظارت المالية خصصت 47 قروش من أنتاج محصول

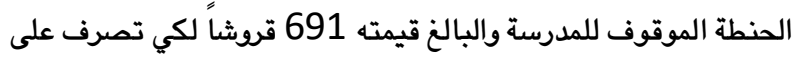
مدرس المدرسة تحديدأ كشرط من شروط الواقف.

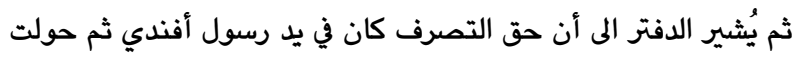

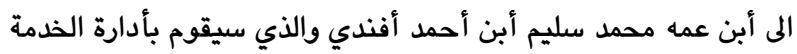

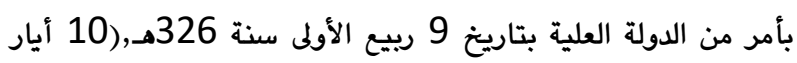
1908

وفي التسلسل 518 تم التأكيد مرة أخرى على صرف 47 قرش

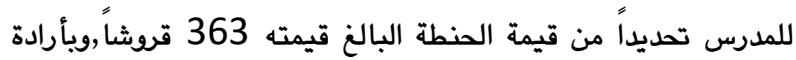

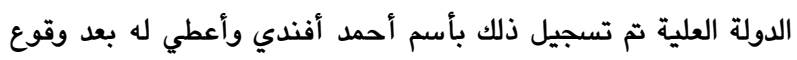

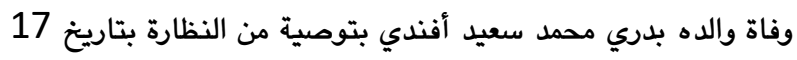
شوال سنة 332هـ,(7 أيلول 1914) وللنظارة الجليلة علم

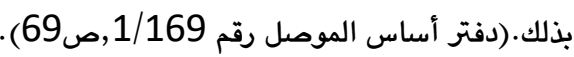
ت. ت جامع قرية الطوير :

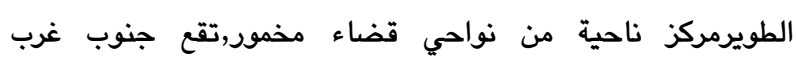
أربيل,جنوب شرق الموصل على شاطئ الزاب الكبير بوهي مركز قبائل

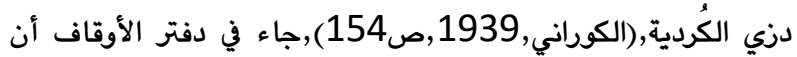
أملاك قرية الطويرالواقع في أربيل ضمن سنجق كركوك وقف الكف

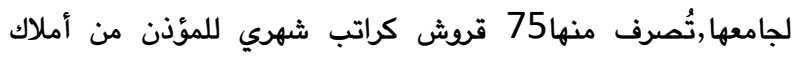

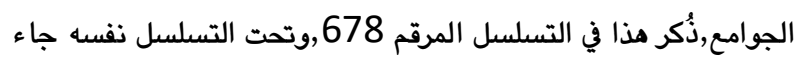
أن القيد جُدد وأن الشيخ ملا سعيد ترك وظيفته كمؤذن وتم توجيهها

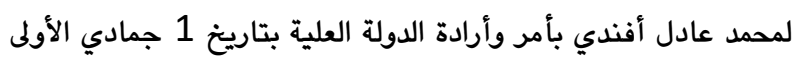
سنة 331هـ,(7 نيسان 1913). ثم جاء تحت التسلسلين 688 و 1913) 689 أنه تم تجديد القيد (التسجيل) (ألمان وتوجيه (أعطاء) وظيفتي الأمامة والخطابة في الجامع المذكور لعبد

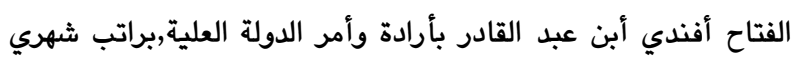

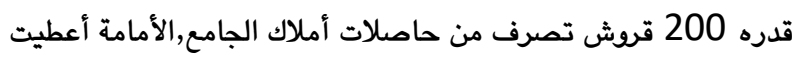

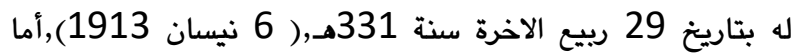


تقع السليمانية $110 \quad$ في 1569 كم,(فرنسيس,2017,ص569),وتبعد عن بغداد حوالي 370 كم,أسسها البابانيون في الريع الأخير من القرن الثامن عشر وتحديداً

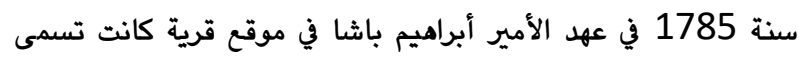

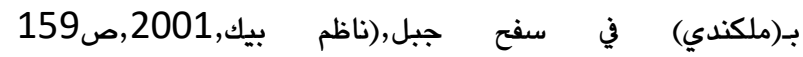
بابان,1986,ص154),أي أن تأسيسها كان معاصراً للحكم العثماني في كوردستان والعراق,وفي أواخر العهد العثماني كانت تشكل أحدى السناجق الهامة لولاية الموصل,وكانت تتألف من أقضية السليمانية التي كانت مركزاً للسنجق وكُلعنبر وشاربازار ومعمورة الحميد

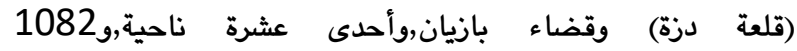
قرية,(Eroglu,2012,s162),وقد جاء ذكر 11 جامعاً ومسجداً ومدرسةً وتكية لسنجق السليمانية في دفتر أوقاف ولاية الموصل وهي كالآتي : ومدرسك

\section{أ. تكية قطب العارفين الشيخ أحمد هندي / سورداش:} سورداش مركز ناحية في محافظة السليمانية,وتقع بالقرب من طريق السليمانية-دوكان,وتبعد عن $40 \quad$ السليمانية كم,(بابان,1986,ص167),وقد ورد ذكرها في كتاب ( Osmanli (yer adlari

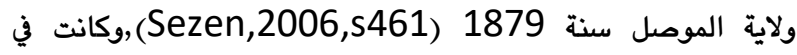
بعض القرى التابعة لها مثل قرى سركلو وثدلة مراكز دينية لسادات

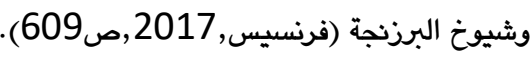
أما في دفتر اوقاف الولاية فقد ورد ذكر سورداش تحت التسلسل المرقم

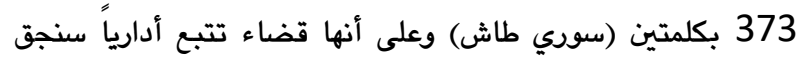
السليمانية,وقد دُفن فيها قطب العارفين حضرة الشيخ أحمد هندي والشيخ محمد صالح أفندي باني التكية,وتم تصنيف المكان كمشيخة,ولتوفير الطعام للتكية المذكورة يُعتمد على واردات 15 فداناً من الأراضي في أطراف التكية كان قد تبرع بها محمد المذكوربويعد وفاة المومى اليه لم يخلف وراءه ولد,فاخذ حق التصرف بذلك صديقه الملا عزيز أفندي بتوجيه وأرادة علية بتاريخ 2 شوال 303هـ,(3 تموز واهديه 1886),ويعد وفاة المومى اليه (الملا عزيز أفندي) تم توجيه حق بق بله التصرف تلك الى أبنه عبد الرحمن أفندي بتوجيه وأرادة وتوصية النظارة بعد ثبوت أهليته لذلك, في 27 رمضان سنة 332 النهـ,(18 آب الب

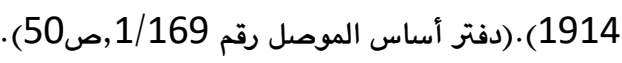

ب. تكية وجامع الشيخ كاك أحمد أفندي(الجامع الكبير): يعتبر من أقدم الجوامع في مدينة السليمانية, أسست في زمن أبراهيم باشا الباباني المتوفي سنة 1802, وفيها قبور عدد من بعن باشوات البابانيين,سمي الجامع تيمناً بأسم الشيخ كاك أحمد أبن الشيخ معروف النودهي المولود في السليمانية سنة 1793,وهو من العلماء الكبار في علوم التفسير والحديث والفقه,ونتيجة لشهرته طلب منه
إيلو),وقد حكمتها حضارات عبر تاريخها الطويل,وشهدت غزوات وهجمات عديدة لأقوام وملل وثقافات مختلفة,(للتفصيل حول ذلك راجع:أسماعيل,1970,صن4-40-44),ويقع جامع القلعة في القسم الغربي من القلعة,مساحتها حوالي 1250م,يعتقد البعض أنها بُنيت قبل أكثر من 800 سنة,فيما يعتقد آخرون أنها أُسست سنة

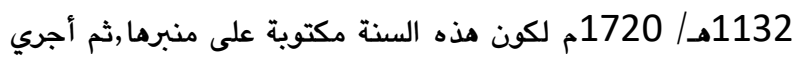
عليها بعض التغيرات سنة 1802 في عهد الملا أبو بكر الثالث,وفي سنة منده 1845 تم توسيع حرمها ووضع لها منارة أيضاً,كما أجريت عليها

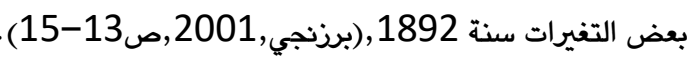
وقد تم ذكر جامع فيها بأسم جامع القلعة تحت التسلسل المرقم 522 في دفتر أوقاف ولاية الموصل,وأُشير الى أنها تقع في قلعة قصبة أربيل التابع لسنجق شهرنود (كركوك),وأن وظيفة الخطابة في الجامع المذكور قد جُدد أعطائها للملا أبو بكر أفندي بالخط الهمايوني( بأمر سلطاني

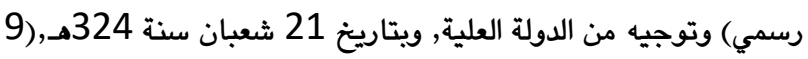

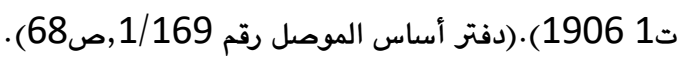

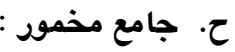
مركز قضاء ضمن محافظة أربيل ويقع جنوب غرب المحافظة بين نهري الزاب الأعلى والزاب الأسفل,وبين سلسلتي جبال حمرين وقرجوغ,تبتعد عن أربيل مسافة 67 كم,وتضم هذه المنطقة سهل قراج الزراعي

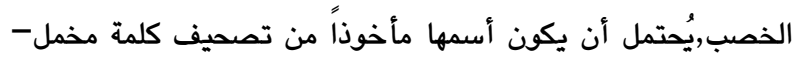
مخمر-مخمور,الذي هو قماش ملون,لأن سهل مخمور يكتسب ألواناً زامية في فصل الربيع,ويُرجح أن أسم مخمور مأخوذ من (مرغ ومور) التي تعني محل الطيور في اللغة الكردية,ويُستبعد أن يكون الأسم مقتبس من كلمة الخمر لأن أهالي تلك المناطق مسلمون,وكذلك لعدم وجود المواد الأولية التي تصنع الخمور مثل العنب والتمور فيها ,(بابان,1956, ج1, ,صود275). ورد ذكر جامع مخمور في دفتر اوقاف الولاية تحت التسلسل المرقم 820 على أن الجامع الشريف تقع في قرية مخمور ضمن شعبة شمامك (ناحية تابعة لمحافظة أربيل) في ولاية الموصل,وقد تم تجديد التسجيل الجامع هذا بأسم عبد المجيد أفندي كخطيب بخط همايوني (بأمر سلطاني رسمي),وبراتب شهري قدره 100 قروش تُصرف من نظارت المعارف (وزارة التربية فيما بعد) بتاريخ 14 جمادي الآخرة سنة 332هـ,(9 أيار 1914),ثم ورد تحت خانة الملاحظات من دفتر الوقف أنه في القدم (في السابق) كانت تُصرف للمعلم في الجامع هذا 3000 قروش من خزينة مالية وزارت المعارف,ثم ثم تخفيض المبلغ

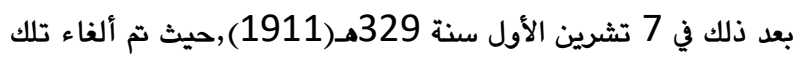
الوظيفة والأبقاء على وظيفة الخطابة بقرار من شورى الأوقاف.(دفتر

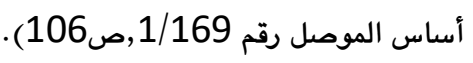




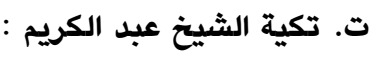
سمي في الفترات المتأخرة بمسجد عبد الكريم أبن الشيخ عبد القادروقد لكد

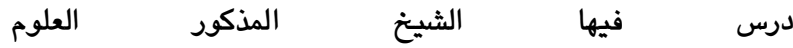
الدينية,(د.ئاراس,2019,ص41),ويمقتضى ما ورد في دفتر أوقاف الولاية ويالتسلسل المرقم 485 تقع التكية هذه في محلة حسين في قرية كوك تبة (هي مركز ناحية سنكاو في قضاء جمجمال,وتعني أسمها التل

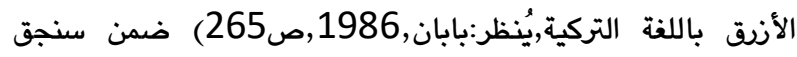

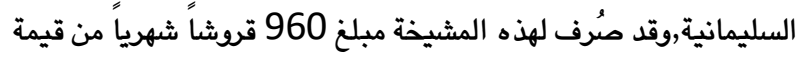
الحنطة ومن خزينة المالية الجليلة,وبعد وفاة الشيخ حسين أفندي, تم تم أعطاء التكية لأبنه الكبير سيد عبد الكريم أفندي وجُدد القيد بأسمه

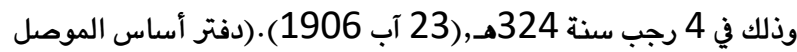

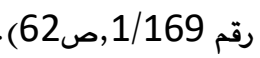

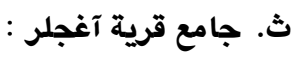
آغجلر هي من أحدى النواحي التابعة لقضاء جمجمال في الوقت الحاضر

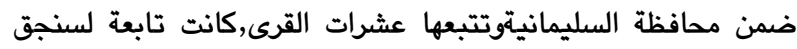
السليمانية في العهد العثمانيثم أقتطعت منها والحقت بقضاء

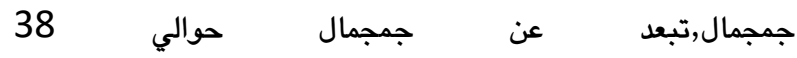
كم,(بابان,1986,ج1,ص23) تم ذكر هذا الجامع في دفتر أوقاف ولاية الموصل تحت التسلسل 535

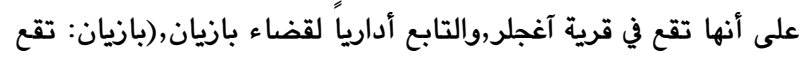

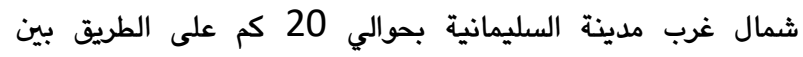
السليمانية وكركوك),ضمن سنجق السليمانية,كما ذُكر فيها أن وظيفة الخطابة في الجامع هذا أعطي لسليمان أفندي أبن الملا عزيز بالخط

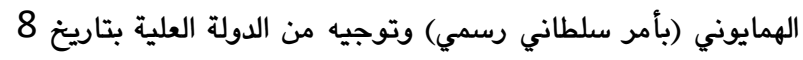
صفر سنة 327هـ,(28 شباط 1909),ثم في التسلسل الذي يليه 536 نص الدفتر على أن وظيفة الأمامة كانت قد وجهت أيضاً لسليمان أبن الملا عزيز بأرادة الدولة العلية وتوصية من النظارة بتاريخ 28

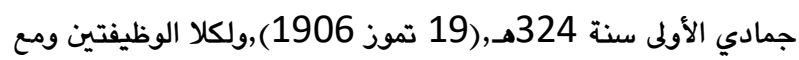

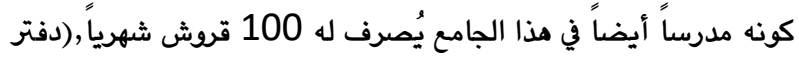

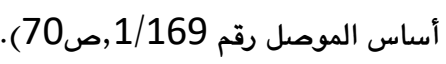
وفي موقع آخر ويتسلسلات آخرى بعيدة عن التسلسلات المشارة اليها

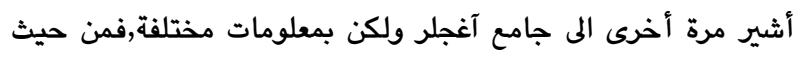

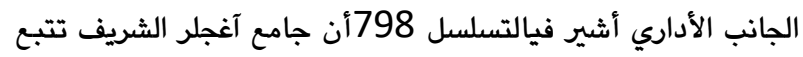

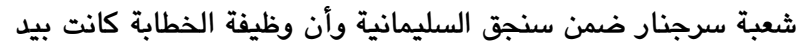
سليمان أفندي,ويعد وقوع وفاته تم تكليف ولده الكبير عارف أفندي بذلك وذلك بخط همايوني (بأمر رسمي سلطاني),وقد تم تجديد

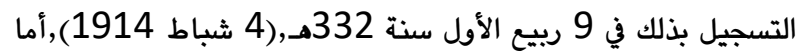
وظيفتي الأمامة والتعليم في الجامع فقد وجهتا في التسلسلين 799 و 800 للمومى اليه أيضاً عارف أفندي وذلك بأشارة علية وتوجيه
السلطان العثماني عبد الحميد الثاني 1876-1909 زيارته في أستانبول غير أنه لم يستطع تحمل أتعاب الطريق فأرسل نيابة عنه

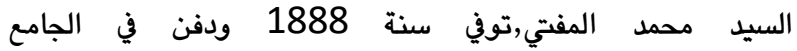
نفسه, (زكي,1951,ص224),ويعتبر الشيخ معروف النودهي وكاك

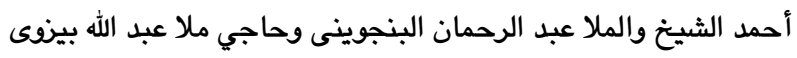
من أبرز مدرسيها,(ره شه,1984,به شى1,رال125),وكان الجامع المذكور تحتوي على مكتبة أحتفظ فيها كتب نفيسة,ويأمر من السلطان

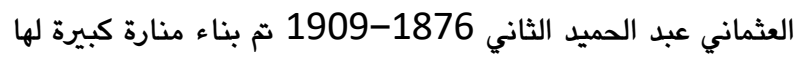

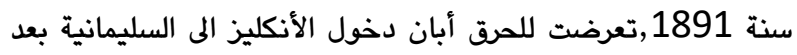

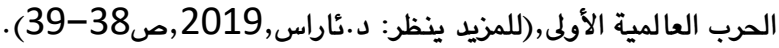
ورد ذكرها في دفتر أوقاف ولاية الموصل ثلاث مرات,أولهما تحت

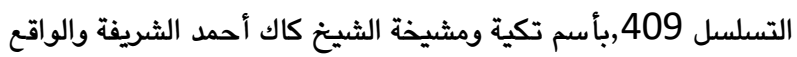

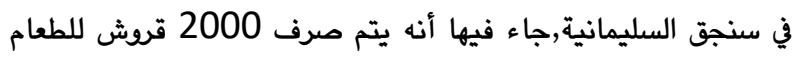

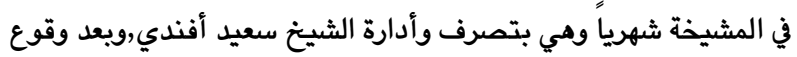

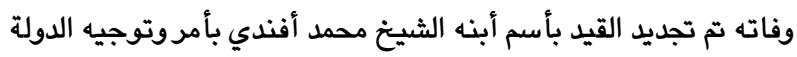

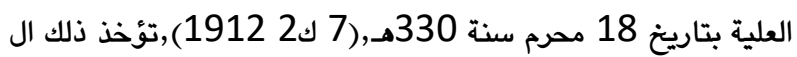
2000 قروش من أعشار القرى الموقوفة على المشيخة منذ 15 ربيع الأول سنة 327,5 نيسان 1909).(دفتر أساس الموصل رقم 1/169, 1/54) كما ورد ذكرها تحت تسلسل آخر والمرقم 725 وصفحة وموقع آخر

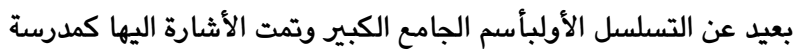

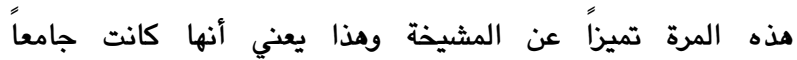
ومشيخةً مدرسة كللدراسات الأسلامية في الوقت ذاته روفيها تم التأكيد على تجديد القيد للحاج سيد حسن أفندي أبن الشيخ محمد مدرساً

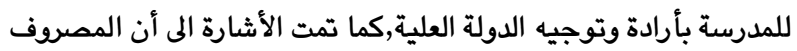
السنوي للمدرس كان 720 قروشاً في السابق,فأضيفت اليه 480 قروشاً أخر بعد ذلك ليصبح المجموع 1200 قروش في 10 جمادي 120

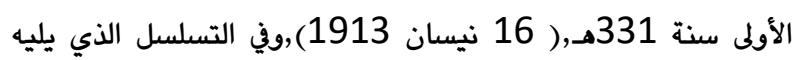
726 أُشير الى أن وظيفة الأمامة في الجامع المذكور وجهت الى الملا

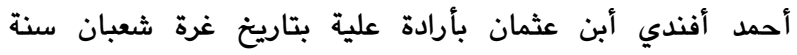

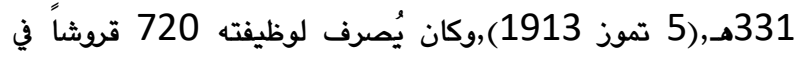
السابق,فأضيفت اليه 480 قروشاً أخرى ليصبح مجموعهما 1200 توند

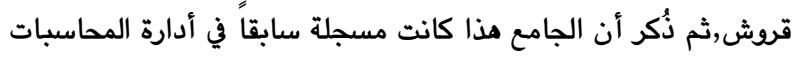

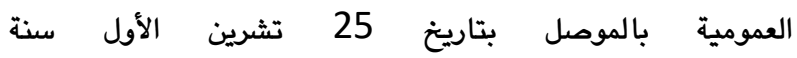

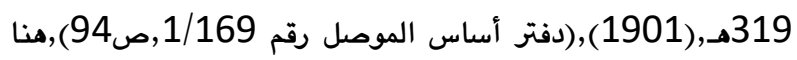
يلاحظ أن الدولة العثمانية كانت تعتمد الشهور الميلادية أحياناً في

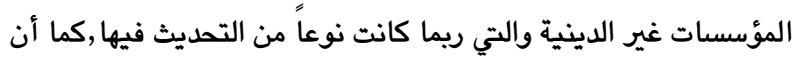
زيادة مخصصات الأكل في هذه الوقفية تُشير الى أنها كانت عامرة

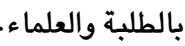


ح. مدرسة وتكية بياويلة / قضاء كُلعنبر: بياويلة قرية تقع شمال شرق مدينة حلبجة,ورد ذكر مدرسة وتكية بأسم بياويلة في دفتر أوقاف ولاية الموصل على أنهما تقعان في القرية المذكورة

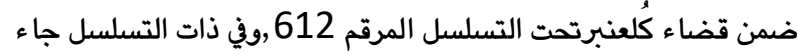
أن المدرسة المذكورة معني بدراسة العلوم الدينية,وأن سيد حسن

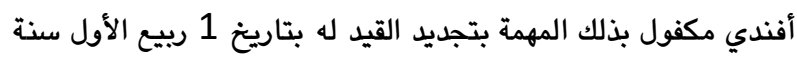
329هـ,(1 آذار 1911) وتُصرف له مقابل ذلك 300 قروش شهرياً. وتحت التسلسل الذي يليه 613 جاء أن مصاريف التكية تُصرف من قبل يوسف.......(لا يقرأ),ويتصرف بها الشيخ محمد جميل أفندي

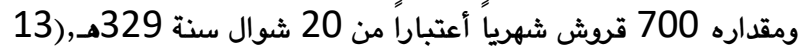

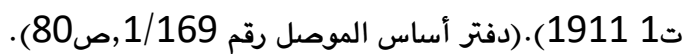

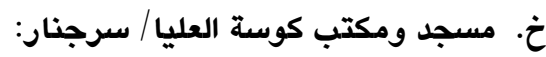
كانت سرجنار في أواخر العهد العثماني ناحية ضمن سنجق السليمانية في ولاية الموصل وكانت تتبعها 139 قرية حسب ما جاء في سالنامة 1310هـ/Eroglu,2012,s 30), 1892). في التسلسل المرقم 658 من دفتر وقف الولاية ورد ذكر مسجد ومكتب

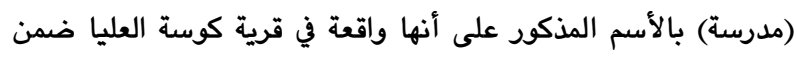
شعبة سرجنار في سنجق السليمانية,كما ذُكر فيها أن وظيفة الأمامة في المسجد جُدت للملا محمد خاكي أفندي (من أهالي حلبجة,ومن مواليد سنة 1845 كان من ألمع العلماء والأدباء ومتمسكاً بالطريقة

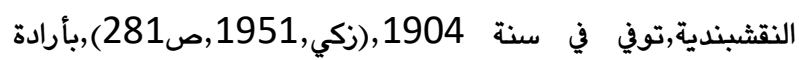
وتوجيه الدولة العلية,على أن تُصرف له شهرياً مبلغ قدره 100 قروش من مخصصات أملاك العلماء والجوامع بتاريخ 15 ثعبان سنة 325هـ, (22 أيلول 1907). ثم ورد تحت خانة الوقوعات من الدفتر أن المومى إليه الملا محمد الخاكي توفي ونتيجة لعدم مقدرة أبنه الكبير على القيام بأداء المهام التي كان والده مكلفاً بها تم توجيه وتكليف الملا عبد الرحمن أبن عبد

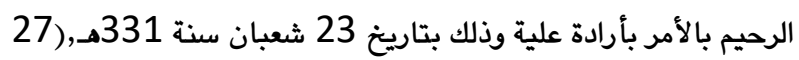
تموز 1913). ويعد ذلك يُشير الدفتر في خانة الوقوعات أيضاً أن المومى اليه الملا عبد الرحمن أبن عبد الرحيم ترك الخدمة وأختار الأقامة في مكان آخر وعليه تم أختيار رفيقه الملا صالح أفندي في مكانه بأمر من الدولة العلية وتوجيه وتوصية النظارة وذلك بتاريخ 29 جمادي الآخرة سنة

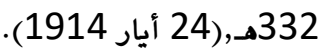
وأخيراً وفي خانة الملاحظات من الدفتر أُشير الى صرف 200 قروش شهرياً للأمام والمعلم من مخصصات أملاك الجوامع والعلماء في القرية المذكورة,كتب ذلك بتاريخ 7 شعبان سنة 328هـ,(13 آب من سمبع

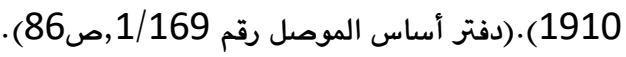

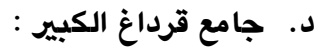

وتوصيةالنظارة,وذلك بتاريخ 29 صفر سنة 332هـ,(26 ك2 1914),ويحسب ما جاء في الدفتر فأن المبلغ الذي يتقاضاه صاحب هذه الوظائف الثلاثة هي 200 قروش شهرياً, وأن ذلك مسجل في مديرية المحاسبة المالية بتاريخ 18 حزيران سنة 329هـ, (1911),وفي خانة فرئ الملاحظات جاء أنه ويعد التشاور مع الأوقاف تم صرف الراتب الشهري من ميزانية وزارة المعارف أعتباراً من التاريخ أعلاه.القيود الوقفية

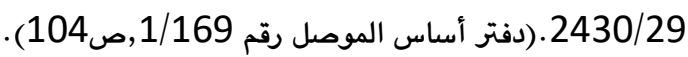
ج. جامع سليم خان ياوز الأول/ كلعنبر : يقع كُلعنبر (خورمال الحالية) على بعد قرابة 18 كم شمال غرب حلبجة (بابان,1986,ج1,,ص104),في جبال هورامان المتاخمة للحدود

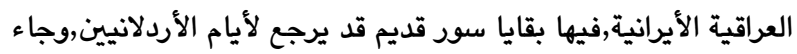
في كتاب (موسوعة المدن والمواقع في العراق)أن فيها جامع قديم بأسم جامع السلطان سليم الثاني العثماني الذي حكم ما بين السنوات

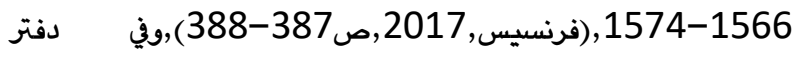
أوقاف ولاية الموصل جاء أنها تسمى بأسم جامع السلطان سليم الأول الياوز الذي حكم في الفترة 1512-1520,لكننا نعتقد أن الجامع مبني على الأرجح في عهد الأمير الباباني سليم باشا الذي حكم ما بين السنوات 1743-1747,وأن ما كتب قد يكون نتيجة لغط أو تشابه

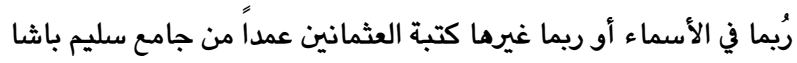
الباباني الى جامع سليم الياوز,أذ يندر أو ينعدم في كوردستان وجود جوامع أو مؤسسات بأسماء للسلاطين العثمانين وخاصة في منطقة نائية وعرة جداً في جبال هورامان. أما فيما يخص بالمعلومات الواردة حولها في دفتر الأوقاف موضوعة هوران الدراسة فقد أُشير الى أن الجامع الشريف هو جامع حضرة السلطان

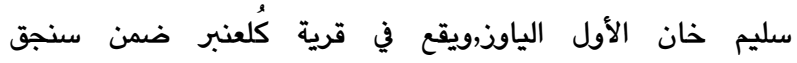
السليمانية,والجامع تعد من الأملاك الهمايونية (السلطانية) ومن

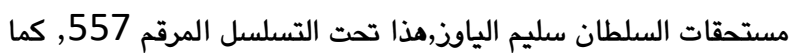
جاء مقابل التسلسل المذكور أن حق التصرف بهذا الجامع كان بيد يحيى أفندي سابقاً وقد توفي بلا ولد ولهذا أصبح وظيفة الخطابة لوريثه الموظف الشيخ عبد الرحيم أفندي بموجب الخط الهمايوني(بأمر سلطاني رسمي) بتاريخ 17 صفر 1328 , 27 شباط 1910),ثم الثن ورد تحت التسلسل 558 أن وظيفة الأمامة كانت قد وجهت للمومى لألي اليه الشيخ عبد الرحيم أفنديبأرادة علية بتاريخ 29 جمادي الأخرة سنة 326هـ,(28 تموز 1908),ويعدما وفي التسلسل 559 جاء أن أن الندئ المومى اليه الشيخ عبد الرحيم كان قد وجهت اليه مهمة التدريس أيضًا بأرادة علية بتاريخ 29 جمادي الأولى سنة 326هـ,(28 حزيران 1908),وأمام التسلسلات الثلاثة جاء أن 500 قروش تُصرف شهرياً للوظائف الثلاثة الخطابة والأمامة والتدريس مجتمعة..(دفتر أساس التساث آنسات الموصل رقم 1/169,ص70). 


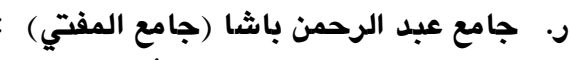
من المساجد العريقة في السليمانية,أُسست من قبل المبل المبل الملا محمود ثير

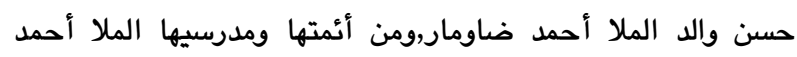

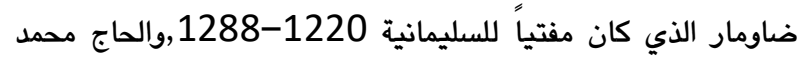
أمين مفتي السليمانية 1250-1315,وعبد العزيز مفتي السليمانية

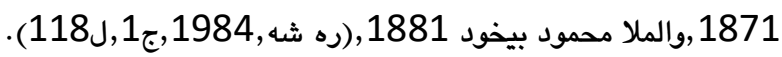
أُشير الى الجامع المذكور تحت التسلسل 761 في دفتر أوقاف ولاية الموصل,ذُكر فيها أنها ذا أسمين,لكنها مشهورة بالأسم الثاني بوأنها تقع في محلة طويَذة في نفس قصبة السليمانية في سنجق السليمانية,كما

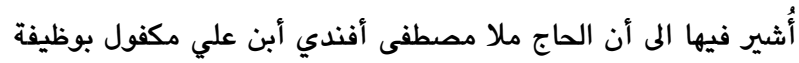

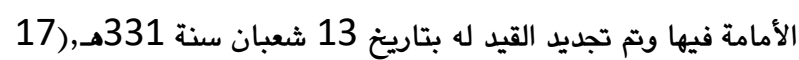

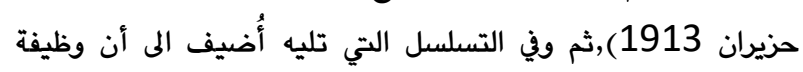

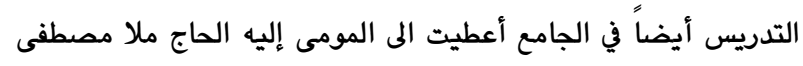

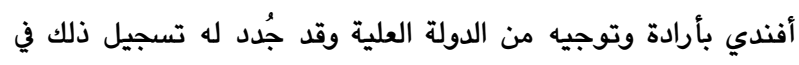

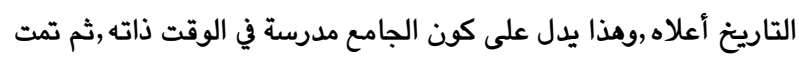

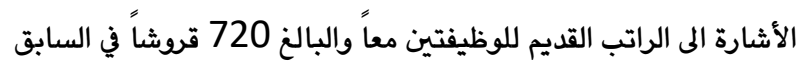

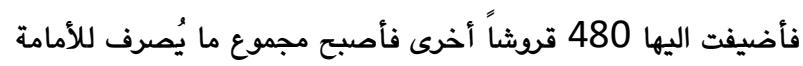

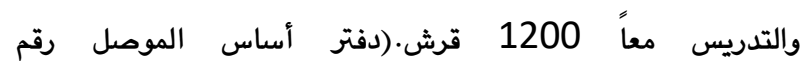
1/169,صو98).

ز. مشيخة وخانقاه مولانا خالد أفندي النقشبندي : أسست المشيخة من قبل محمود باشا عبد الرحمن,ومن أبرز خطباء

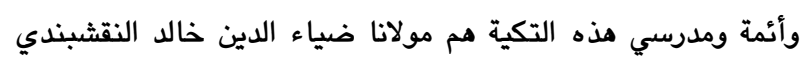
الجاف الذي يُعتبر أول من نشر النقشبندية في السليمانية والأناضول

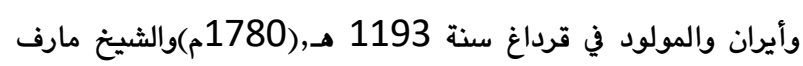

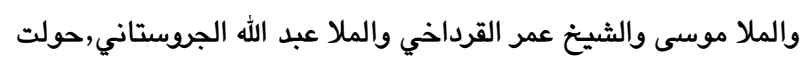

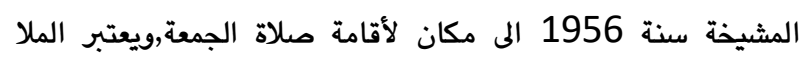

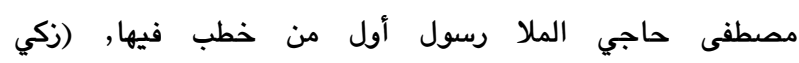
بك,1951,ص225 : : ره شه, 1984,به شى 1,11121). جاءت ذكرها في التسلسل المرقم 866 في دفتر الأوقاف بوصفها مشيخة نقشبندية واقعة في حي دركزين, (كانت تسمى ب دركزين الهمدان لأن

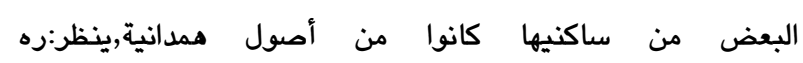
شه,1984,167) في قصبة السليمانية, وأعتمادا على الأمر القديم

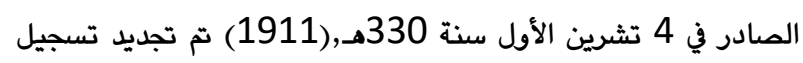

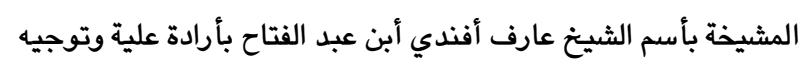

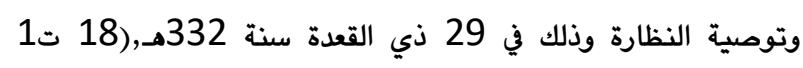

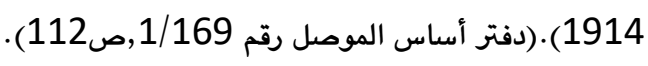

كانت قرداغ من النواحي التابعة للسليمانية,تبعد عن السليمانية حوالي 30 كم,وتعني أسمها الجبل الأسود باللغة التركية,أما أسمها القديم النيانية

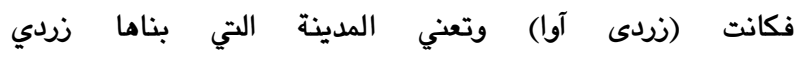
(بابان,1986,ج1,صرئ228),وهي في الوقت الحاضر من المدن

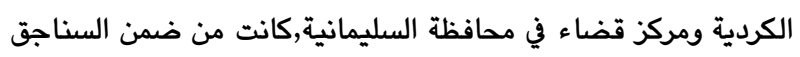
التابعة لأيالة بغداد في القرن السابع عشربوفي سنة 1830 أصبحت

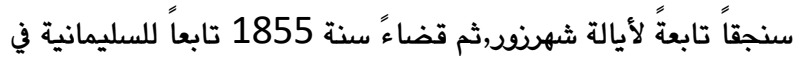
أيالة بغداد مع شهرنوربولكن حولت الى ناحية سنة 1879 تابعةً

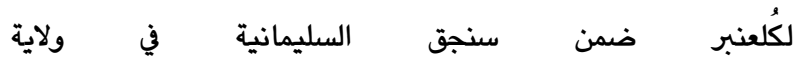
الموصل, (sezen,2006,s276). أما بخصوص جامع قرداغ فقد ورد ذكرها تحت التسلسل المرقم 711 ألمولر

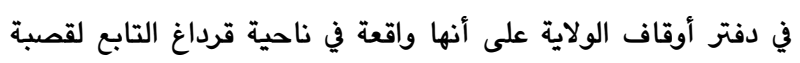

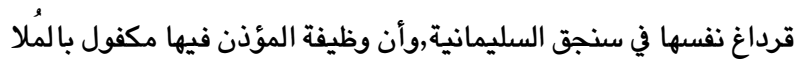

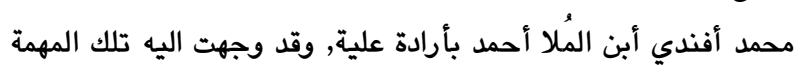

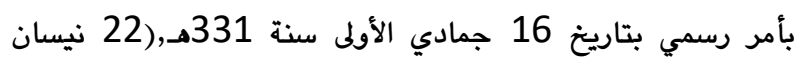

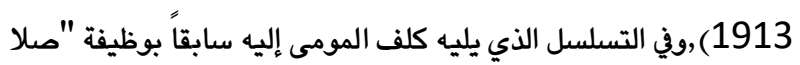

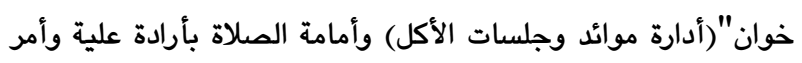

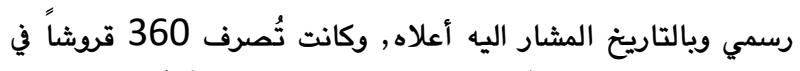
السابق للمهمتين سنوياً, فأضيفت اليها 240 قروشاً أُخر منذ سنة

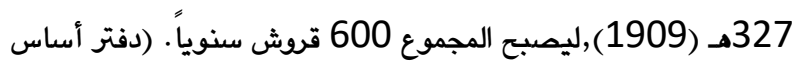

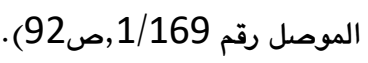
ذ. مشيخة سيد أحمد أفندي/ السليمانية :

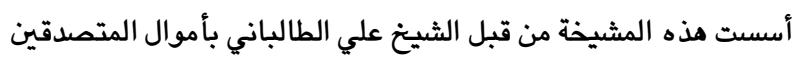

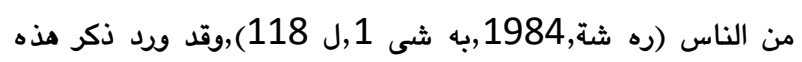

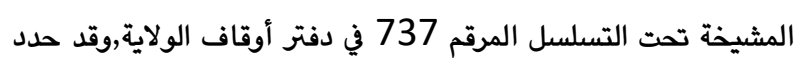

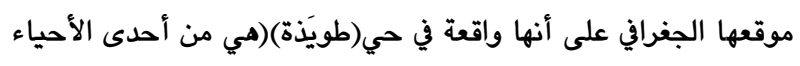
القديمة في السليمانية,سمي بهذا الأسم نسبة الى شجرة الطويذّة أو ربما

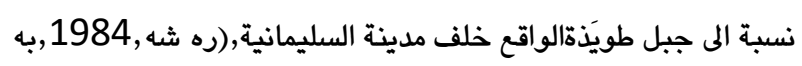
شى 1,167) في سنجق السليمانية,وتُصرف للطعام فيها من خزينة

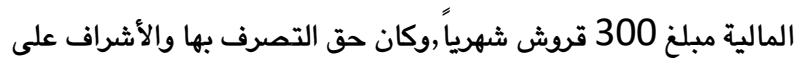
المشيخة منوطة بالسيد أحمد أفندي الذي كان نقريان نقيب الأشراف

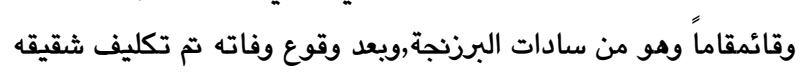

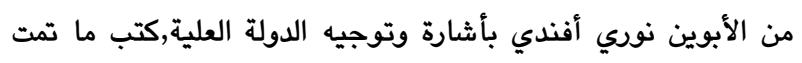

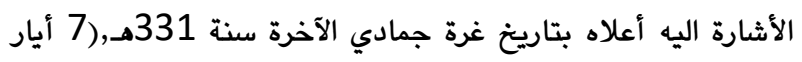

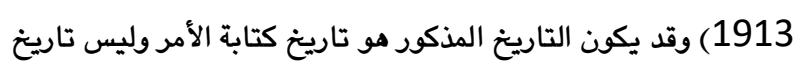

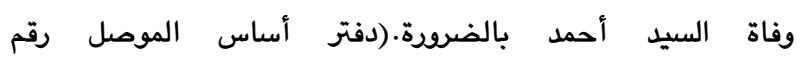

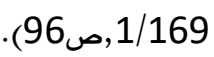


4. بشير يوسف فرنسيس,موسوعة المدن والمواقع في العراق,ط1, (لندن:2017). 5. جمال بابان, أصول أسماء المدن والمواقع العراقية,ط 2.

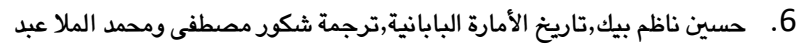
الكريم المدرس,ط1, (هولير:2001).

7. سعيد الحاج صديق زاخوي,زاخو الماضي والحاضر,ط2, (دهوك :2009).

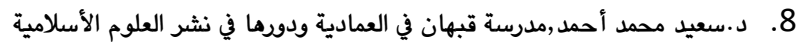
في كوردستان,ط1, (دهوك:2013).

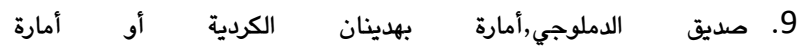
العمادية,ط2, (أربيل:1999).

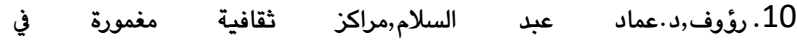
كردستان,ط1, (أربيل:10

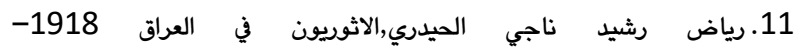
1936,ط1,1(القاهرة:1977).

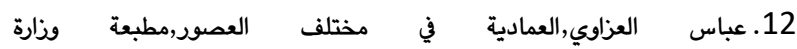
الثقافة, (هولير:1998). 13. عبد الرزاق الحسني, العراق قديماً وحديثاً, (صيدا:1956). 1956). 14.علي سيدو الكوراني,من عمان الى العمادية أو جولة في كردستان الجنوبية,(عمان:1939).

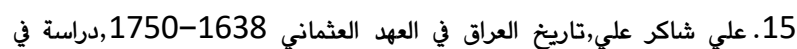
أحواله السياسية,ط1,(نينوى:1985).

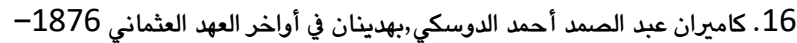
1914, ط1, (أربيل:2007). 17. محمد أمين زكي,تاريخ السليمانية,ترجمة :الملا جميل الملا أحمد الروزبياني,(بغداد:1951).

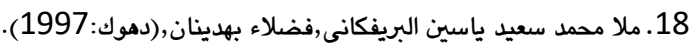
19. د.نزار أيوب كولي,د.غسان وليد الجوادي,مقدمة في تاريخ زاخو خلال العهد

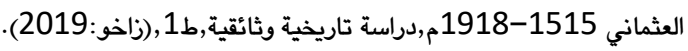

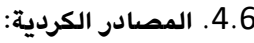
1. نئكرةمى مةحمودى سالحى رةشة,شارى سليَمانى,ثيَّاضونةوة د.عيزةدين مستةفا رةسول,ضاثى 2, 2 (بةغدا:1984).

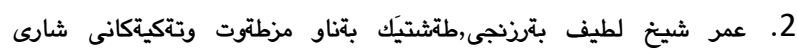
هةوليَر,(هةوليَر:2001).

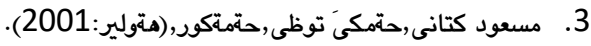

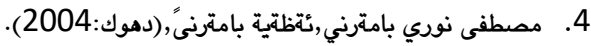

5.6 - 5. - 5 المصادر الترية:

1. Tahir sezen,osmanli yer adlari,(Ankara:2006). $\square$

2. Cengiz eroglu,murat babaucoglu,orhan ozdil,osmanli vilayet salnamelerinde Musul,(Ankara:2012). $]$

3 Mehmet dikmen,osmanlica-turkce sozluk,(Istanbul:2012).

$$
\text { 6.6. الدوريات والمؤتمرات: }
$$

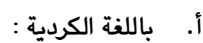

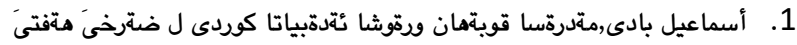

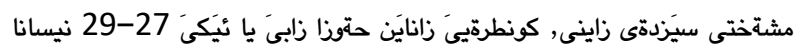
2018,بةرطى دووىَّ.

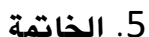

بعد أكمال الدراسة هذه توصل الباحث الى أستنتاجات لعل من أبرزها هي 1. يعد دفاتر الأوقاف من السجلات والوثائق العثمانية الهامة والمحتوية على كم كبير من المعلومات النادرة حول الأوقاف وما يتعلق بها من أبنية ومدراء ومدرسين ورواتب وتفاصيل أخرى تخدم جوانب مختلفة من التاريخ الحديث للشعوب التي حكمتها الدولة العثمانية. 2. رغم أهمية دفتر الأوقاف موضوعة الدراسة ألا انها لا تضم ولا تحتوي على كافة المؤسسات الوقفية التاريخية التي كانت موجودة آنذاك في ربوع ولاية الموصل,بل أكتفت بالبعض منها فقط,وهذا يعني أن بقية الجوامع والمساجد والمدارس والتكايا الغير المذكورة في دفتر الأوقاف مذه لم تكن تابعة للدولة العثمانية وغير مشمولة بدعم الحكومة من حيث توفير رواتب رجال الدين والمدرسين والحاجيات الأخرى لتلك الجوامع أو المدارس أو الطرق الصوفية. 3. إن التفاصيل المذكورة في دفاتر الأوقاف والتي شملت جوامع ومدارس في مناطق نائية من كوردستان تدل على قوة الجهاز الأداري العثماني واطلاعها على دقائق الأمور على الرغم من أن الدولة المذكورة كانت تمر بفترة عصيبة وصعبة من عمرها كونها كانت قد أقتربت من نهايتها وأفول نجمها قبيل أندلاع الحرب العالمية الأولى.

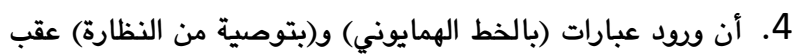
تعين رجال الدين والمدرسين تؤكد لنا بلا شك أن الدولة كانت تُدار بمركزية شديدة ريما غير مبررة لدرجة أن تعين رجل دين أو مدرس علوم دينية في مسجد أو مدرسة في مناطق نائية أحياناً في جبال كردستان وفي مدنها وقصباتها البعيدة جغرافياً عن مركز الدولة العثمانية (أستانبول) كانت بحاجة الى الموافقة السلطانية رغم مرحلة الضعف

$$
\text { التي دخلتها الدولة المذكورة من جميع النواحي. }
$$

1.6. الوثائق غير المنشورة:

- المديرية العامة لأرشيف الأوقاف, دفتر أساس الموصل رقم 1/169. -Vakiflar genel mudurlugu arsifi musul esasi 169/1. 2.6. الوثائق المنشورة: 1. موصل ولايتى سالنامه سى,1308هـ.

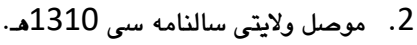
3. موصل ولايتى سالنامه سى 1312هـ.

3.6. - المصادر العربية والمعربة: 1. أنور المائي,الأكراد في بهدينان,ط2, (دهوك:1999).

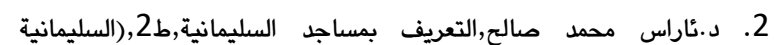

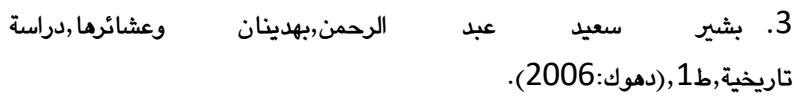




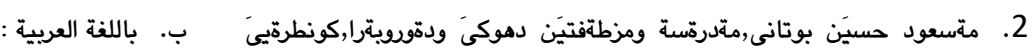
1. عبد الفتاح علي يحيى,الملا يحيى المزودي وسقوط أمارة بادينان,مجلة

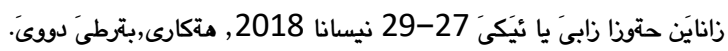
كاروان,العدد 41, (أربيل :1986).

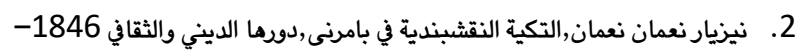
1958),المؤتمر الأول لعلماء حوض الزاب,هكاري 27-29 نيسان 2018 نئنسية 2018.

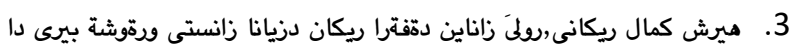

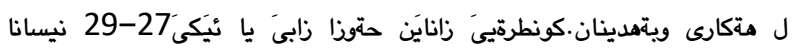
2018,بةرطىَ دوويَ.

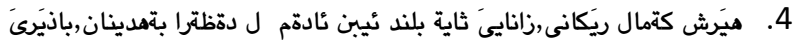

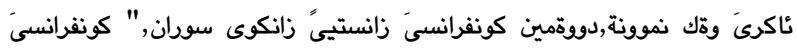

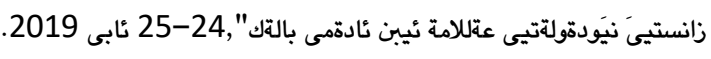

-

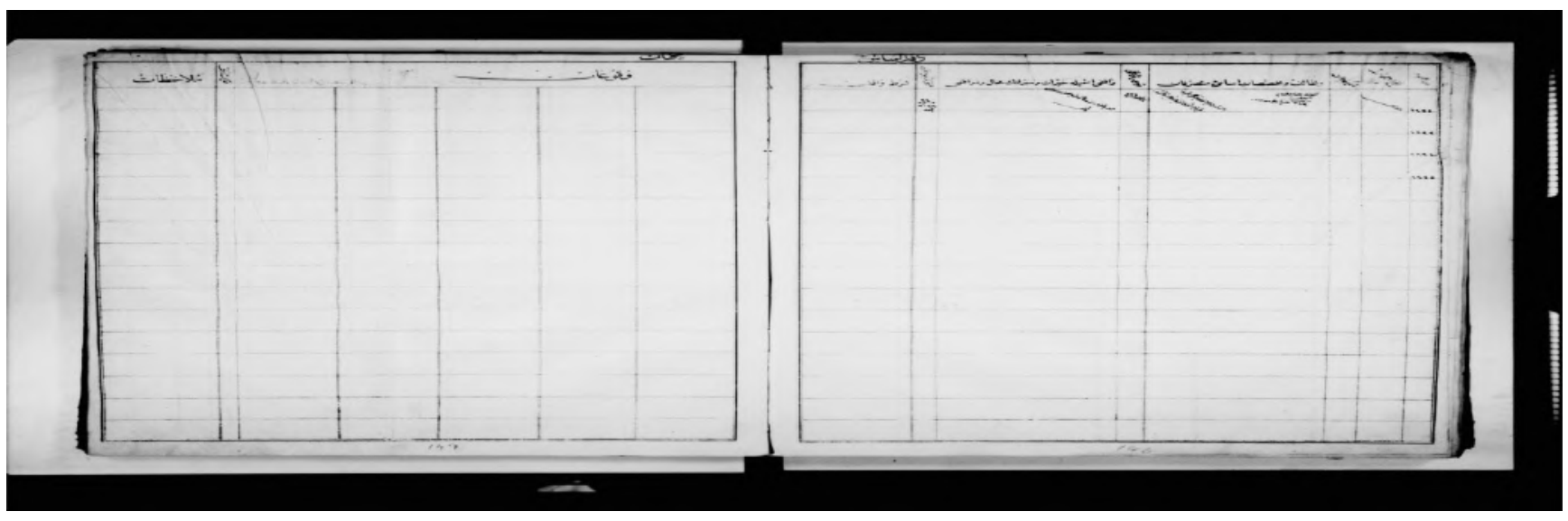

ملحق رقم 1 ( المعلومات الواردة في دفتر الأوقاف بخصوص مدرسة قبهان )

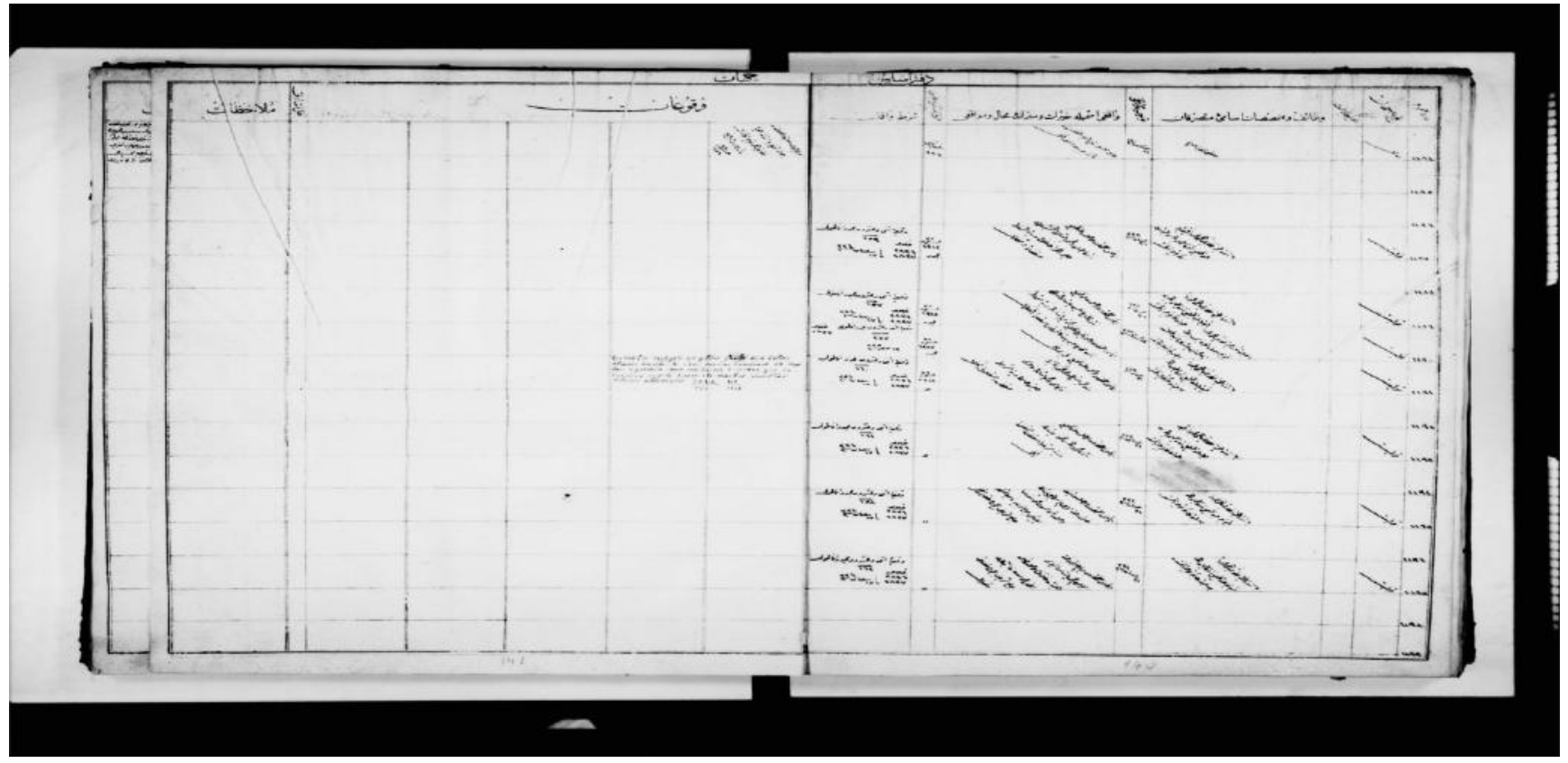

ملحق رقم 2 ( المعلومات الواردة في دفتر الأوقاف بخصوص مدرسة الجديدة ) 


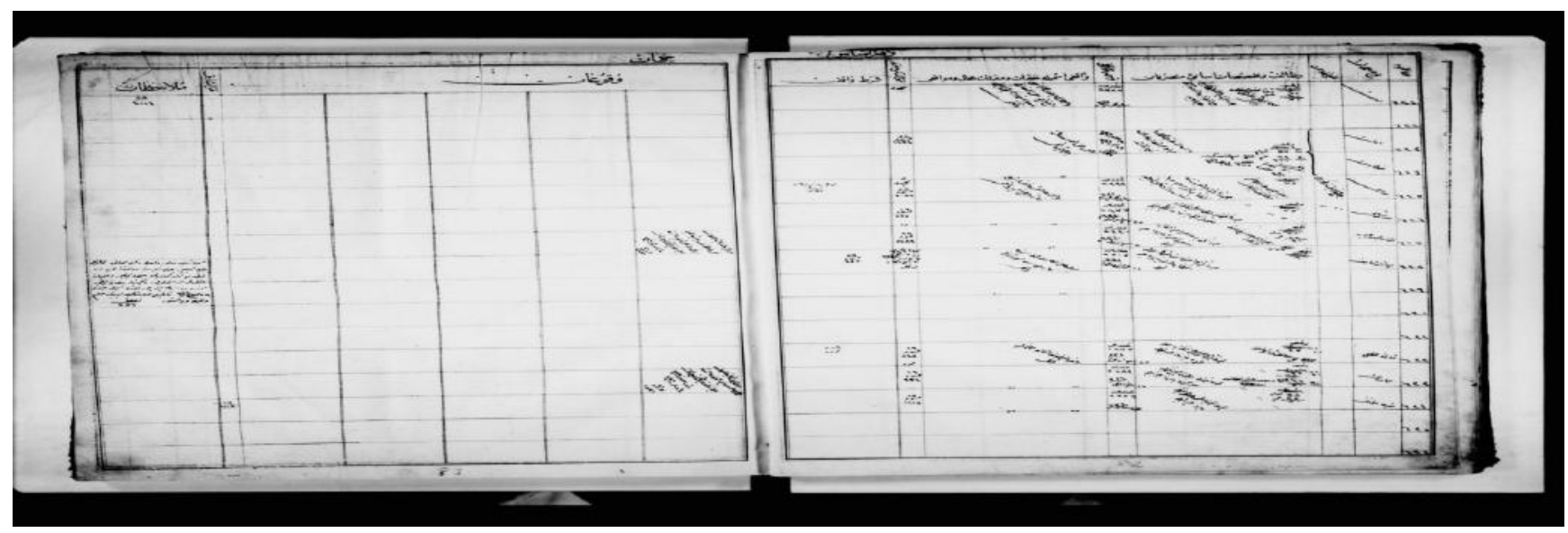

ملحق رقم 3 ( المعلومات الواردة في دفتر الأوقاف بخصوص جامع عقرة الكبير )

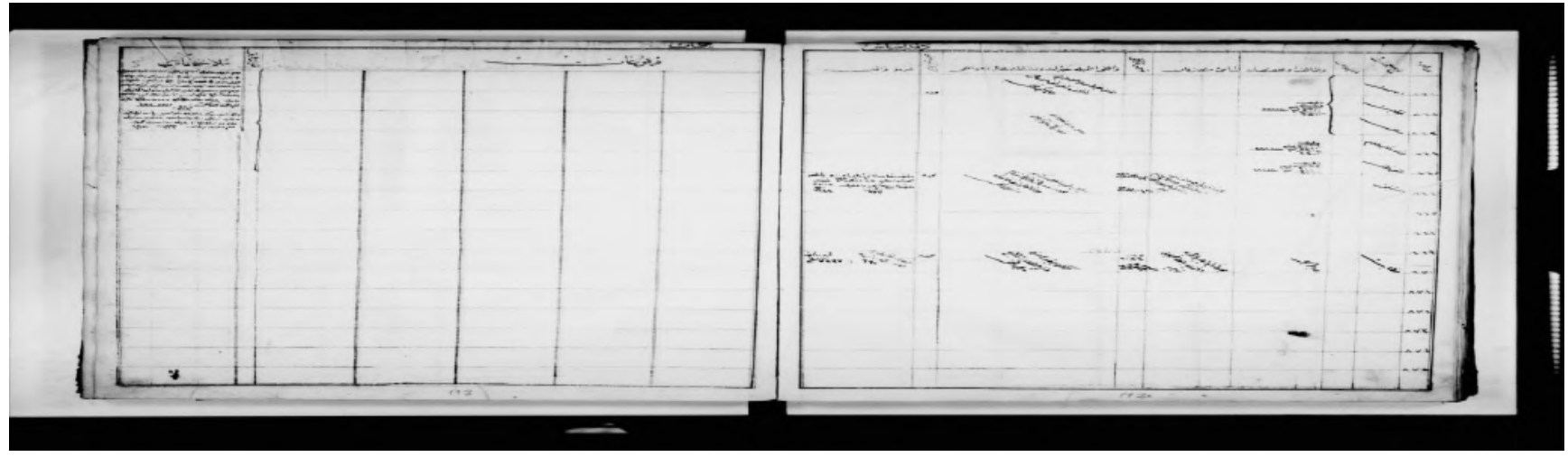

ملحق رقم 4 ( المعلومات الواردة في دفتر الأوقاف بخصوص جامع زاخو الكبير )

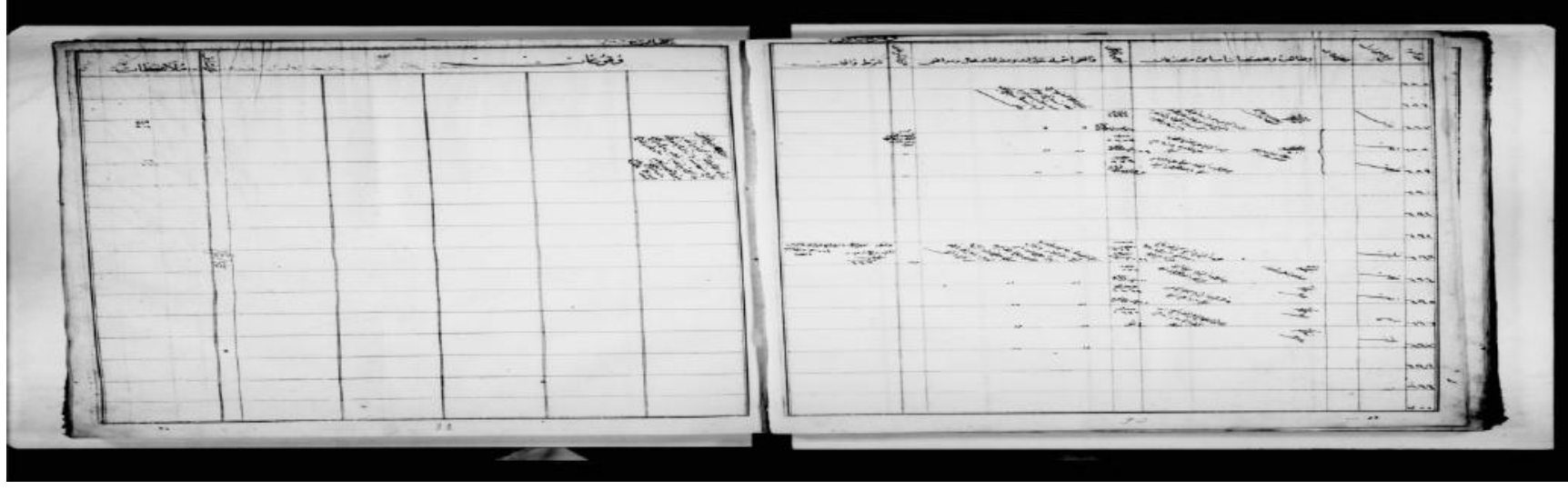

ملحق رقم 5 ( المعلومات الواردة في دفتر الأوقاف بخصوص جامع الكوير وجامع الحاج مولود/أربيل )

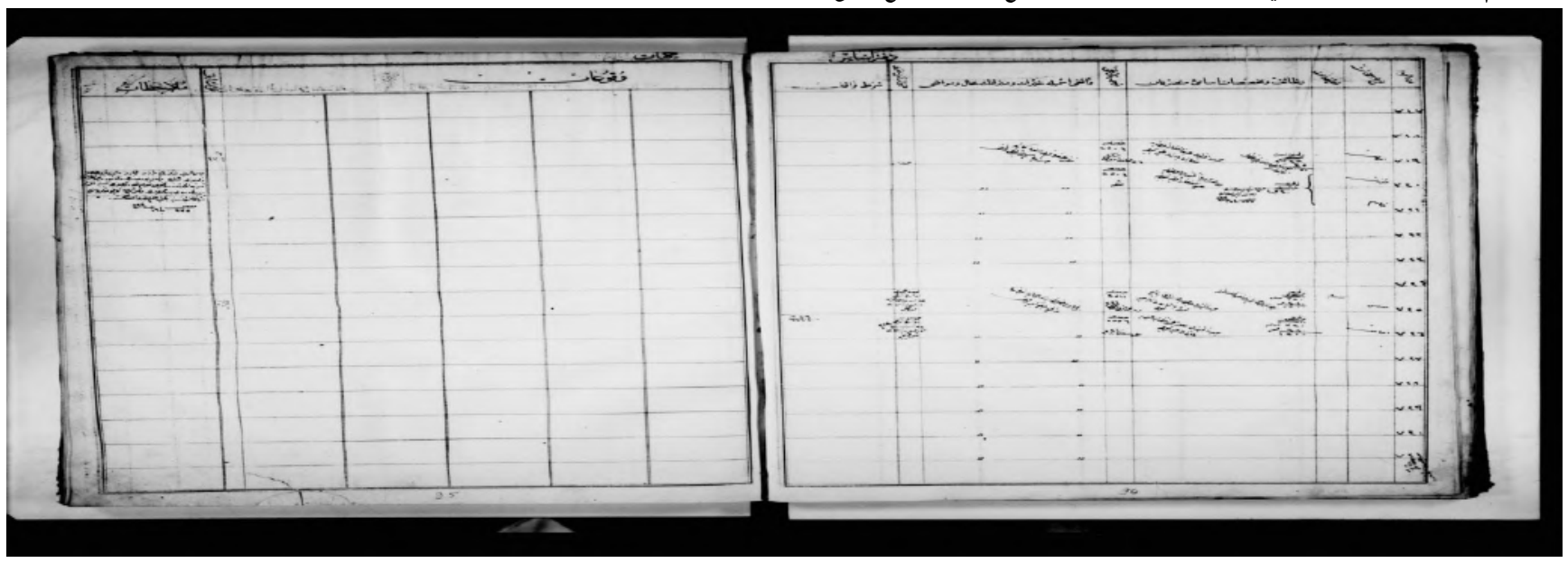

ملحق رقم 3 ( المعلومات الواردة في دفتر الأوقاف بخصوص جامع السليمانية الكبير وجامع جستيان في عقرة ). 


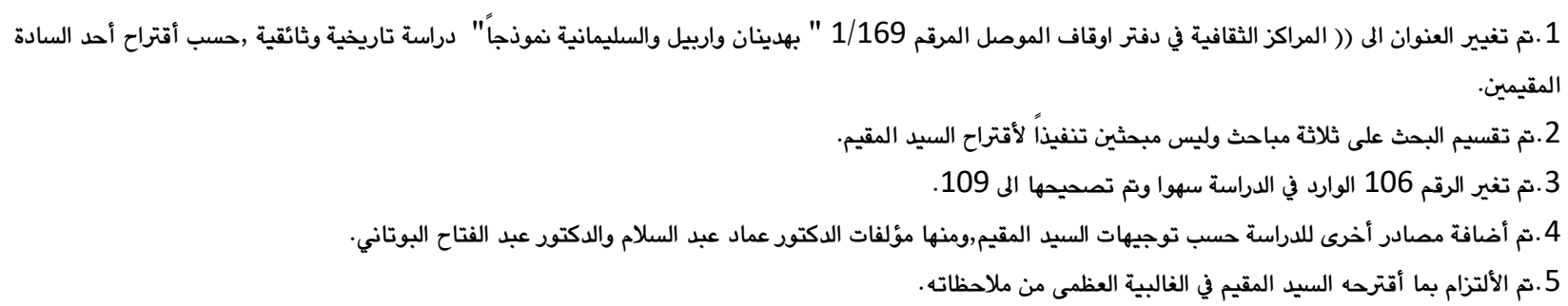

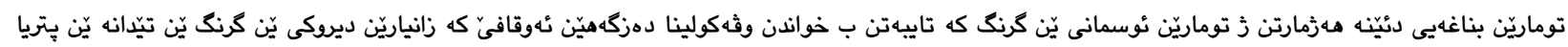

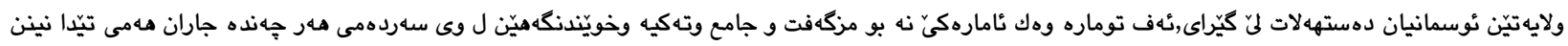

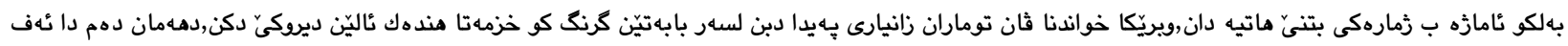

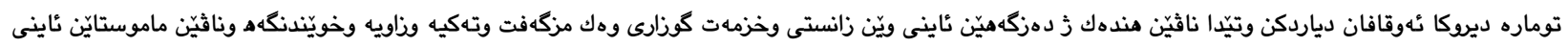

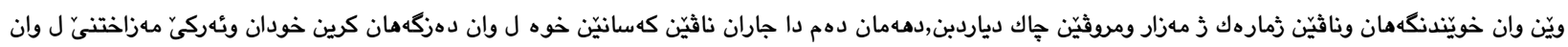

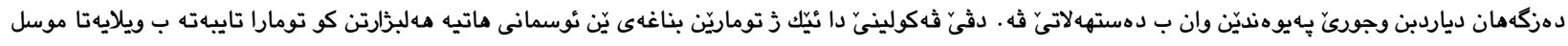

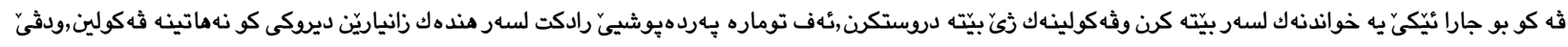

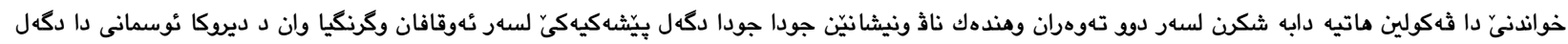

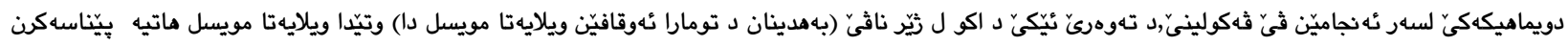

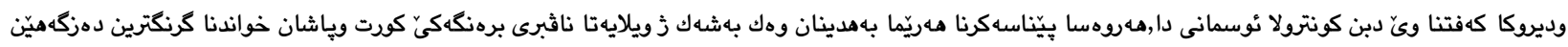

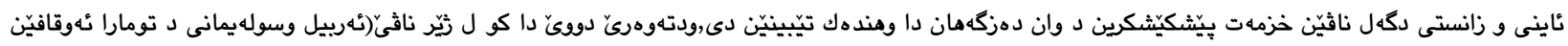

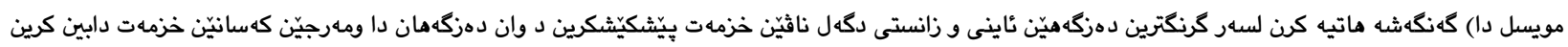

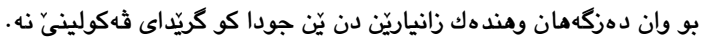

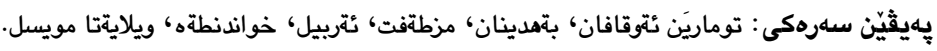

\title{
Cultural centers in the book of endowments of Mosul No. 169/1 "Bhdinan, Erbil and Sulaymaniyah as an example" A historical and documentary study
}

\begin{abstract}
:
The Ottoman notebooks are regarded as important Ottoman records that are specialized in the study of endowments and endowment institutions. These notebooks contain important historical information for most of the vilayets that were ruled by the Ottoman Empire, manifesting an inventory of mosques, schools and hospices, even if all of them are not covered or comprehensively mentioned. In viewing these notebooks, valuable historical information is served, and the history of endowments, which include the names of the most remarkable religious and educational institutions and service facilities, is reflected. These notebooks and recordstackle the names of mosques, hospices, holy shrines, the names of institution administrators, the quality of their relationship with the ruling authorities, and the names of donators, whodeposited their money or property for serving these institutions. In this study, one of the Ottoman notebooks (the notebook of Mosul Vilayet) was chosen. For descriptive research purposed, the study was divided into three main sectionswith an introduction to the endowments and their importance in the Ottoman history, and a conclusion reached by the researcherthroughout the study. In the first section, titled "Behdinan in the Endowment Book of the Mosul Vilayet), the Mosul Vilayet and the date of its joining to the Ottoman state were clearly defined to briefly study the most important religious and scientific institutions. Also, focus is on the most significant endowments dedicated to serving these institutions with the endowers' names and the notes related to them. In the second section, titled"Erbil and Sulaymaniyah in the Endowment Book of the Mosul Vilayet", light was mainly shed on the most important religious and scientific institutions, the most significant endowmentsdevoted to serving these institutions, presenting the names and terms of the endowments, with some other minor details related to the study.
\end{abstract}

Keywords: Behdinan, Endowment Books, Erbil, Mosques, Mosul Vilayet Schools. 